Research Article

\title{
Initial Parameters Affecting the Multilayer Doubly Curved Concrete Shell Roof
}

\author{
Thi My Dung Do $\mathbb{D}^{1},{ }^{1}$ Thanh Quang Khai Lam $\mathbb{D}^{1},{ }^{1}$ Thi Thu Nga Nguyen $\mathbb{D}^{2}{ }^{2}$ \\ Van Thuc Ngo $\mathbb{D}^{1},{ }^{1}$ Hoang Hung Vu, ${ }^{3}$ Trong Chuc Nguyen $\mathbb{D}^{4},{ }^{4}$ and Van Duan Doan ${ }^{5}$ \\ ${ }^{1}$ Mien Tay Construction University, 20B Pho Co Dieu Street, Vinh Long, Vietnam \\ ${ }^{2}$ University of Transport Technology, 54 Trieu Khuc Street, Hanoi, Vietnam \\ ${ }^{3}$ Thuy Loi University, 175 Tay Son Street, Hanoi, Vietnam \\ ${ }^{4}$ Le Quy Don Technical University, 236 Hoang Quoc Viet Street, Hanoi, Vietnam \\ ${ }^{5}$ Vietnam Maritime University, 484 Lach Tray Street, Hai Phong, Vietnam \\ Correspondence should be addressed to Thanh Quang Khai Lam; lamthanhquangkhai@gmail.com
}

Received 25 May 2021; Accepted 8 August 2021; Published 26 August 2021

Academic Editor: Kim Hung Mo

Copyright (c) 2021 Thi My Dung Do et al. This is an open access article distributed under the Creative Commons Attribution License, which permits unrestricted use, distribution, and reproduction in any medium, provided the original work is properly cited.

\begin{abstract}
Doubly curved shell roof structures have been widely studied and applied in civil buildings, because of their compressive capacity. As a spatial structure, it should increase the space, reduce the thickness of the shell, and create the architecture for the building. In particular, reinforcement is needed to repair the shell surface, forming the multilayer curved shell roof structures. In this multilayer curved shell roof, it is necessary to investigate the influence of thickness of layers, the influence of the location of the steel fibres concrete layer, and the influence of steel fibres content contained in concrete on the state of stress and strain and build relationships, load-vertical displacement and stress in the $\mathrm{x}$ and y directions of the shell in the investigated cases. So, this paper presents an ANSYS numerical simulation study related to the state of stress and strain in double-layer doubly curved concrete shell roof with the initial parameters being changed such as the thickness of the layers, the location of the steel fibres concrete layer in the structure (the steel fibres concrete layer that is placed above and below the normal concrete layer), and the steel fibres content contained in concrete shell with the size of $3000 \times 3000 \mathrm{~mm}$, which is simulated by ANSYS after being experimentally conducted on this curved shell roof; the results of experimental and simulation study are verified by each other. Research results show that the thickness of the steel fibres concrete layer is placed below the normal concrete layer, the percentage of steel fibres contained in the concrete is $2 \%$, and the bearing capacity of the curved shell is optimal.
\end{abstract}

\section{Introduction}

Vlasov, who laid the groundwork in his research on shell types, proposed the shell theory, which is composed of thin shells. With this shell theory, Vlasov proved that these shells are mainly compressive or tensile, and the bending moment in the shell is very small and can be ignored in calculations. Vlasov [1] built a system of 2 equations with two stress and displacement ( $\varphi$ and $w$ ) functions with the load distributed over the shell surface.

Since then, plenty of shell studies have occurred, including shell analysis with the different curvature or seismic response of smart nanocomposite cylindrical shell, and using HDQ-Newmark methods in conveying fluid flow [2], cylindrical and spherical lattice shell $[3,4]$, the strain-stress state of concrete dome structure simulated by ANSYS [5], and doubly curved shells with square and rectangular plane was studied by the approximation method; this method is developed on the basis of finite difference method that studied and developed by Gabbasov. In the 1980s, the essence of this method was to solve general quadratic differential equations. To solve this general differential equation, Gabbasov used the meshing method and thereby established the relationship between the points; from there, 
the results were converted from general differential equations to the system of linear equations for each point on the grid [6].

In addition, the shell structures have been studied by many authors by experimental method, finite element method [7, 8], by Sap2000 software [9], and by numerical simulation method, ANSYS, for umbrella shell in vibration analysis [10]; many authors have studied various parameters such as repairing and strengthening of elliptical paraboloid reinforced concrete shells [11], R-Funicularity [12], prediction of the buckling behavior of shell [13], funicular concrete shell foundation under ultimate loading [14], classical shell theory for instability analysis of concrete pipes [15], bearing capacity of the initial imperfect lattice shell [16], optimized high-performance concrete shells [17], stability of steel shell structures [18], including large scale shell [19], and investigation of the geometrically nonlinear behavior of thin-shell structures [20]. Through the analyzed studies, the studies analyzed the state of stress and strain and considered the parameters affecting the shells. However, these studies only studied single-layer shells.

According to research on curved shells, these shells are damaged during use, need to be repaired, or need to be waterproof, heat resistant, or strengthened for these shells to increase bearing capacity and increase the life of the buildings, so they are necessary to add one or more layers above or below the existing shell layer. Ambartsumyan [21] has also suggested the multilayer shell hypothesis. Many studies have been done on various types of shells such as cylindrical shells, spherical shells, doubly curved shells, and elliptical paraboloid shells using analytic methods, numerical methods, finite element methods, approximation methods, and other methods based on Ambartsumyan's laminated shell theory. Ambartsumyan assumed that layers were referred to equivalent layers according to their modulus of elasticity, such as the layerwise theory of laminated doubly curved shells [22], analysis of laminated doubly curved shells in both static and dynamic conditions [23], the bending and free vibration analysis of laminated composite shells [24], multilayer shell element for shear walls in open sees [25], stress-strain state of three-layered shallow shells [26], and mesh-reinforced Sandwich concrete shell roof [27]. Many researches have used the multilayer shell element in the finite element (FE) model nonlinear analysis to approach nonlinear studies [28]. The multilayer shell structure is also an applicability analysis on the multilayer shell structure system in construction, to test the theoretical method with multilayer structures that have been tested by the above theoretical methods [29].

In analyzing the structures of multilayer doubly curved shell roofs, many studies have used analytical methods or numerical methods to solve these curved shell problems. However, with the use of these curved shells in civil buildings, the material of the shell must be analyzed. Currently, steel fibres concrete has the ability to increase bearing capacity and reduce cracks and has good impact resistance; in addition, steel fibres concrete can also work quite well when steel fibres concrete is located in the tension region. In the studies on these steel fibres concrete materials, many studies have used them in flexural multilayer structures such as double-layer beams or three-layer beams. The performance of normal concrete and steel fibres concrete in these laminated beams is quite suitable when repairing damaged concrete beams. These studies have conducted experiments and simulated by ANSYS these multilayer flexural beams $[30,31]$. However, there are other studies on steel fibres concrete materials with nanosilica that can also be applied in this doubly curved shell experiment and simulation $[32,33]$.

Recently, this multilayer doubly curved shell roof is further studied when analyzing the nonlinearity of steel fibres concrete materials and the change of steel fibres content in concrete by ANSYS. The study determined the state of stress and strain in the shell and the sliding ability between two different concrete layers in the shell [34]. However, the shell material must be investigated in both the experimental analysis and ANSYS simulation for the laminated doubly curved shells. Because shell's compressive capacity and reinforcement are needed to repair the shell surface, it is necessary to investigate the influence of the thickness of layers, the influence of the location of the steel fibres concrete layer, and the influence of the steel fibres content contained in concrete on the state of stress and strain and build relationships, load-vertical displacement and stress in the $\mathrm{x}$ and $\mathrm{y}$ directions of the shell in the investigated cases. So, this paper presents an ANSYS numerical simulation study related to the state of stress and strain of double-layer doubly curved concrete shell roof with the initial parameters being changed such as the thickness of the layers, location of the steel fibres concrete layer (the steel fibres concrete layer (SFCL) above and below the normal concrete layer (NCL)), and steel fibres content contained in concrete shell with the size of $3000 \times 3000 \mathrm{~mm}$, which is simulated by ANSYS after being experimentally conducted on this curved shell roof; the results of experimental and simulation study are verified by each other.

\section{Materials and Methods}

2.1. Vlasov Equations in Calculating the Shell Roof Structures. Vlasov [1] built a system of 2 equations with two stress and displacement ( $\varphi$ and $w$ ) functions with the load distributed over the shell surface (equation (1)):

$$
\left.\begin{array}{l}
\frac{\partial^{4} \phi}{\partial x^{4}}+2 \frac{\partial^{4} \phi}{\partial x^{2} \partial y^{2}}+\frac{\partial^{4} \phi}{\partial y^{4}}+E h\left(k_{1} \frac{\partial^{2} w}{\partial x^{2}}+k_{2} \frac{\partial^{2} w}{\partial y^{2}}\right)=0 \\
k_{1} \frac{\partial^{2} \phi}{\partial x^{2}}+k_{2} \frac{\partial^{2} \phi}{\partial y^{2}}-D\left(\frac{\partial^{4} w}{\partial x^{4}}+2 \frac{\partial^{4} w}{\partial x^{2} \partial y^{2}}+\frac{\partial^{4} w}{\partial y^{4}}\right)=-q(x, y)
\end{array}\right\},
$$

where $h$ is the shell thickness, $E$ is modulus of elasticity, $k_{1}$ and $k_{2}$ are main curvature in 2 directions, and $D$ is the flexural stiffness of the shell.

With the above assumption, for doubly curved shell with rectangular plan, Ambartsumyan [21] has introduced a system of equations to solve the problem of multilayer 
doubly curved concrete shell with two functions to find for the vertical load component case $z$ (equation (2)):

$$
\begin{aligned}
& P_{1} \frac{\partial^{8} \psi}{\partial \alpha^{8}}+P_{3} \frac{\partial^{8} \psi}{\partial \alpha^{6} \partial \beta^{2}}+P_{5} \frac{\partial^{8} \psi}{\partial \alpha^{4} \partial \beta^{4}}+P_{4} \frac{\partial^{8} \psi}{\partial \alpha^{2} \partial \beta^{6}}+P_{2} \frac{\partial^{8} \psi}{\partial \beta^{8}}+O_{1} \frac{\partial^{6} \psi}{\partial \alpha^{6}}+ \\
& \quad+O_{3} \frac{\partial^{6} \psi}{\partial \alpha^{4} \partial \beta^{2}}+O_{4} \frac{\partial^{6} \psi}{\partial \alpha^{2} \partial \beta^{4}}+O_{2} \frac{\partial^{6} \psi}{\partial \beta^{6}}+k_{2}^{2} \frac{\partial^{4} \psi}{\partial \alpha^{4}}+2 k_{1} k_{2} \frac{\partial^{4} \psi}{\partial \alpha^{2} \partial \beta^{2}}+ \\
& \quad+k_{1}^{2} \frac{\partial^{4} \psi}{\partial \beta^{4}}=Z
\end{aligned}
$$

where $P_{i}(\alpha, \beta)$ and $O_{i}(\alpha, \beta)$ are parameters that depend on the geometrical size of the shell.

\subsection{The Double-Layer Doubly Curved Concrete Shell Roof Was} Built. Before investigating the initial parameters affecting the state of stress and strain of the shell, this study has been conducted to build a double-layer doubly curved shell model and conduct this shell experiment. The ANSYS simulation and experimental structure design model are followed by TCVN 5574:2018 [35], which is presented in Tables 1 and 2.

The equation for the surface of the doubly curved shell is shown in equation (3):

$$
z=f_{1}\left(\frac{x}{a}\right)^{2}+f_{2}\left(\frac{y}{b}\right)^{2}
$$

where $f$ is the height of the shell at its highest point, $f=f_{1}+f_{2}=600 \mathrm{~mm} ; f_{1}=300 \mathrm{~mm}$ and $f_{2}=300 \mathrm{~mm}$ are the height in both directions; $a$ and $b$ are half the length of the shell's rectangular plan edge.

Double-layer curved concrete shell roof with a plan size of $3000 \times 3000 \mathrm{~mm}$, fixed joint with 4 vertical curved beams, and a constant cross-sectional area of $150 \times 200 \mathrm{~mm}$ are supported on 4 columns with a cross section of $300 \times 300 \times 1300 \mathrm{~mm}$, as shown in Figure 1 .

\subsection{Making the Double-Layer Doubly Curved Concrete Shell} Roof. The shell fabrication process consists of 3 steps: make the formwork according to the shape of the doubly curved shell (equation (3) and Figure 1(a)), the first layer of steel fibres concrete was poured, and then the normal concrete layer is poured last, as shown in Table 1 and Figure 2.

2.4. Installation of Devices and Shell Experiment. Installation diagrams of strain gauges (tensiometers) are measured at the top and bottom surfaces and vertical displacement measuring devices (LVDTs) are measured at the bottom surface of the shell. Because of the influence of measuring devices, the number of measuring positions is arranged as shown in Figures 3(a) and 3(b).

In the condition of using this curved shell roof in the buildings in Vietnam, the load acting on the shell includes the load on the shell itself and the live load on repairing the shell, so the total effective load is $5 \mathrm{kN} / \mathrm{m}^{2}$ or $45 \mathrm{kN}$ of load acting on the shell surface (shell surface area: $9 \mathrm{~m}^{2}$ ). The total load acting on the shell is $5 \mathrm{kN} / \mathrm{m}^{2}$, and depending on the weight of the sand or small concrete blocks, it has been divided into 7 levels in this study.

Load acting on the shell consist of 7 levels: level $1=1.63 \mathrm{kN} / \mathrm{m}^{2}$, level $2=2.17 \mathrm{kN} / \mathrm{m}^{2}$, level $3=2.72 \mathrm{kN} / \mathrm{m}^{2}$, level $4=3.26 \mathrm{kN} / \mathrm{m}^{2}$, level $5=4.35 \mathrm{kN} / \mathrm{m}^{2}$, level $6=5 \mathrm{kN} / \mathrm{m}^{2}$, and level $7=5.44 \mathrm{kN} / \mathrm{m}^{2}$. At the first 4 levels, the load is applied to the shell by small sand and then concrete blocks, as shown in Figure 3(c). All measuring devices at each level are linked to the computers, as shown in Figure 3(d).

In addition, in the process of pouring concrete layer by layer, it is necessary to check the thickness of the layers, and after experimenting, drilling holes are made to check the actual layers, as shown in Figure 3(e).

\subsection{Finite Element Model for Double-Layer Doubly Curved Concrete Shell Roof in ANSYS}

2.5.1. Elements and Models. In numerical simulation by ANSYS, this study used solid65 element to simulate concrete; this is an 8-node element and easy to analyze material nonlinearly and can simulate steel fibres in concrete with a concrete coefficient; this concrete coefficient is applied to the concrete according to the volumetric content that the distributed steel fibres. In analyzing steel fibres in concrete, ANSYS also asked to choose a model for them. Because the steel fibres are distributed in the concrete, this study chooses smeared model in three models of ANSYS, smeared, embedded, and discrete models, as shown in Figure 4.

According to the perimeter of the shell boundary, there are steel bars (Figures 1(b) and 1(c)), so BEAM188 element was used in simulation analysis and this is an element consisting of 2 nodes.

Concrete is a brittle material, so a concrete cracking model must be selected in the analysis. There are two concrete cracking models, discrete and smeared, but the steel fibres are distributed in the concrete, so in this study, the smeared model was selected and shown in Figure 5.

Simulating with two different materials, normal concrete (NC) and steel fibres concrete (SFC), three models are used, continuous model, interface model, and thin-layer model. However, in this research, the NC is on steel fibres concrete, only in contact with each other, so the interface model was chosen, as shown in Figure 6.

2.5.2. Material Properties. In compression result of two materials, SFC and NC, in the experiment (Figure 7), the stress-strain relationship of these two types of concrete is consistent with Kachlakev's model. Therefore, in this study, Kachlakev's model was used in the following models: Hognestad, Todeschini, Kent and Park, and Kachlakev.

In the simulation, the failure surface model is also built, with the 2 types of concrete in this research and the selected solid65 element; the failure criteria of Willam and Warnke are appropriate, as shown in Figure 8.

Meshing: the meshing of elements in the shell and the nodes of the mesh must be together; if the mesh is too thick, the calculation time will be slow. With this thin-shell 
TABLE 1: Geometric and material parameters of concrete shell.

\begin{tabular}{lcccc}
\hline & Concrete grade & Thickness $(\mathrm{mm})$ & Modulus of elasticity $\left(\mathrm{kN} / \mathrm{m}^{2}\right)$ & Concrete type \\
\hline Layer 1 (below) & B30 & 20 & $3.25 \times 10^{7}$ & Steel fibres, 2\% (volume) \\
Layer 2 (above) & B20 & 30 & $2.75 \times 10^{7}$ & Normal \\
\hline
\end{tabular}

TABle 2: Parameters of Dramix steel fibres in shell.

\begin{tabular}{lc}
\hline & $0.5 \mathrm{~mm} \pm 0.04 \mathrm{~mm}$ \\
Diameter $(\mathrm{d})$ & $30 \mathrm{~mm} \pm 2 \mathrm{~mm}$ \\
Length (L) & 60 \\
Ratio (L/d) & $2-4 \mathrm{~mm}$ \\
Hook length $\left(l\right.$ and $\left.l^{\prime}\right)$ & $1.8 \mathrm{~mm}+0.3 \mathrm{~mm}$ \\
Hook depth $\left(h\right.$ and $\left.h^{\prime}\right)$ & $45^{\circ}$ \\
Bending angle $\left(\alpha\right.$ and $\left.\alpha^{\prime}\right)$ & $<30^{\circ}$ \\
Torsion angle & 17400 \\
Number of fibres in $1 \mathrm{~kg}$ & $>1.2 \mathrm{kN} / \mathrm{mm}^{2}$ \\
Tensile &
\end{tabular}

structure, the mesh shape is divided by spatial tetrahedron, and the element size is half the thickness of the thinnest shell concrete layer as shown in Figure 9(a).

Fixed link shell with vertical curved beams: the applied load is distributed on the top surface of the shell at the nodes of the tetrahedron mesh, by a compressive force $P$ uniformly distributed over the shell surface, as shown in Figure 9(b).

\section{Results and Discussion}

3.1. Evaluation of Research Results. The experimental results of the shell roof are compared with ANSYS and Sap2000 software by values of vertical displacement and stresses; total effective load is $5 \mathrm{kN} / \mathrm{m}^{2}$.

(i) Load and vertical displacement relationship of the shell in methods is shown in Figure 10.

Discussion of Result. The study results in Figure 10 show that ANSYS and Sap2000 are similar (here are the numeric methods), so when these numeric methods are compared to the experimental method, there is a difference near the shell boundary and at the top of the shell. There is a larger vertical displacement value near the shell boundary, but a smaller vertical displacement value at the top of the shell, and the value difference between the methods is very small $(0.05 \mathrm{~mm})$. As a result, the vertical displacement values of all three methods are similar.

(ii) Load and stress relationship of the shell in methods is shown in Figure 11.

Discussion of Result. In Figure 11, with the ANSYS and Sap2000 methods, the value of the stresses is similar. However, the value of the experimental method is changed at the location $(x=1.2 \mathrm{~m})$ of the stress $\sigma_{x}$ and at the location $(x=0.6 \mathrm{~m})$ of the stress $\sigma_{y}$, compared with ANSYS and Sap2000 methods from 15 to $20 \mathrm{~N} / \mathrm{cm}^{2}$. These values may be affected by measuring devices, material homogeneity, and so on; given this difference between experimental and numerical methods, further studies are needed, but this change is very small and can be accepted in this study.

The results of this experimental study show that this multilayer doubly curved shell roof from location $0.6 \mathrm{~m}$ to $1.2 \mathrm{~m}$ tends to be affected by boundary conditions, so it also needs further studies on the influence of these boundary conditions.

With the use of this shell roof under the conditions of use in Vietnam, cracks have not appeared in the shell, and it is necessary to continue research in ANSYS with larger load values.

3.2. Investigate the Effect of Thickness of Each Layer. In experimental research and simulated by ANSYS with SFCL $\left(h_{1}\right)$, thickness of $2 \mathrm{~cm}$, under NCL $\left(h_{2}\right)$, thickness of $3 \mathrm{~cm}$, and relationships load-vertical displacement and load-stress in the $x$ and $y$ directions have been built (Case 1). To investigate the influence of thickness of layers on the stress-strain state in the shell, this study continues with 2 investigated cases, Case 2 and Case 3, by ANSYS, as presented in Table 3.

Discussion of Result

(i) Case 1. With the load acting on the shell surface according to the conditions of use in Vietnam of $5 \mathrm{kN} / \mathrm{m}^{2}$, the shell has no cracks. Experimentally, it is difficult to study the shell further, and ANSYS will simulate the shell at larger load levels. So, in the period when cracks appear in the concrete, $\mathrm{P}=14 \mathrm{kN} / \mathrm{m}^{2}$, stress $133.8 \mathrm{~N} / \mathrm{cm}^{2}$, and the first cracks appeared at the SFC layer and along the shell boundary with a vertical displacement at the top of the shell of $0.17 \mathrm{~mm}$ (Figure 12).

(ii) Case 2. Similarly, in the period when cracks appear in the concrete, $\mathrm{P}=12.5 \mathrm{kN} / \mathrm{m}^{2}$, stress $139 \mathrm{~N} / \mathrm{cm}^{2}$, and the first cracks appeared at the SFC layer and along the shell boundary with a vertical displacement at the top of the shell of $0.187 \mathrm{~mm}$ (Figure 13).

(iii) Case 3. Similarly, in the period when cracks appear in the concrete, $\mathrm{P}=17.5 \mathrm{kN} / \mathrm{m}^{2}$, stress $127.6 \mathrm{~N} / \mathrm{cm}^{2}$ and the first cracks appeared at the SFC layer and along the shell boundary with a vertical displacement at the top of the shell of $0.207 \mathrm{~mm}$ 


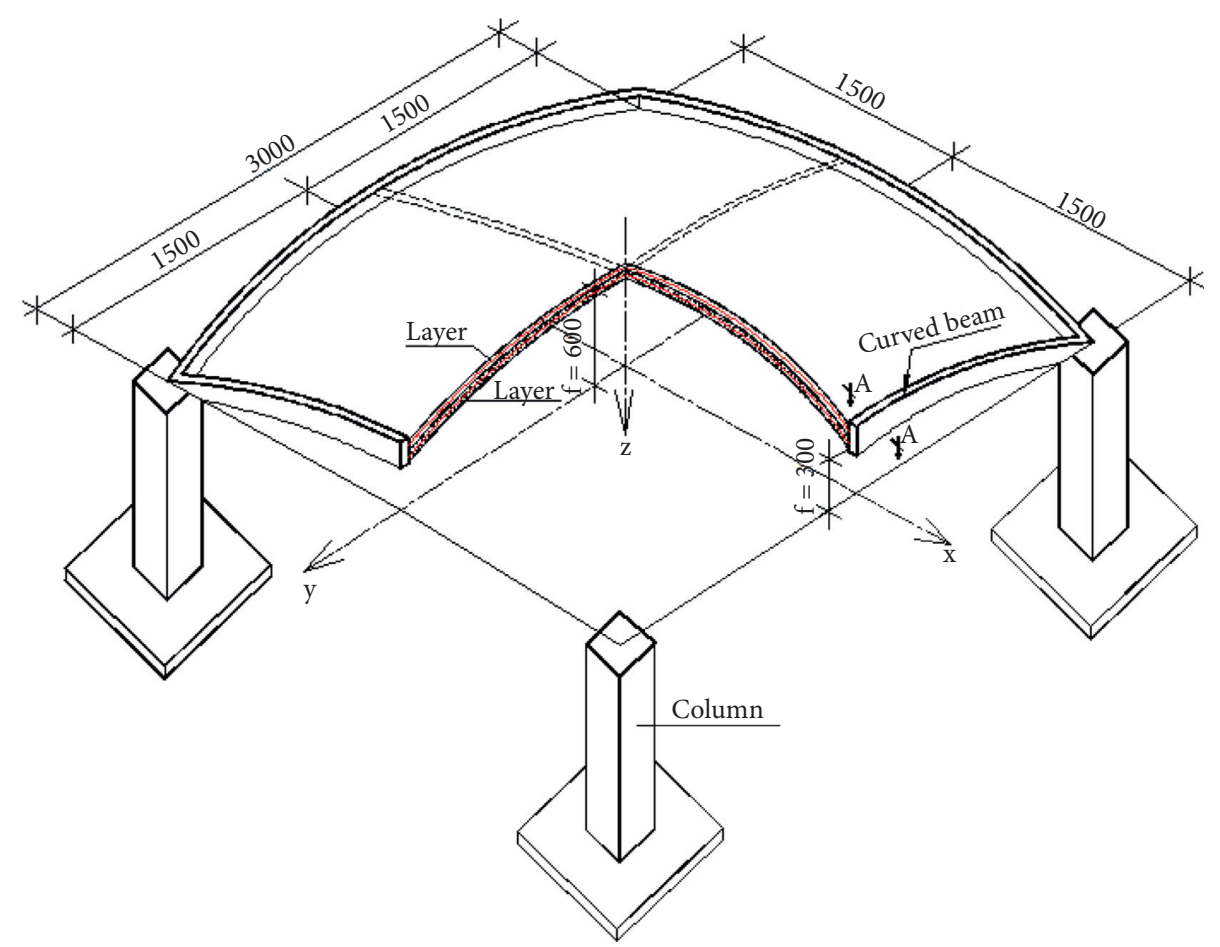

(a)
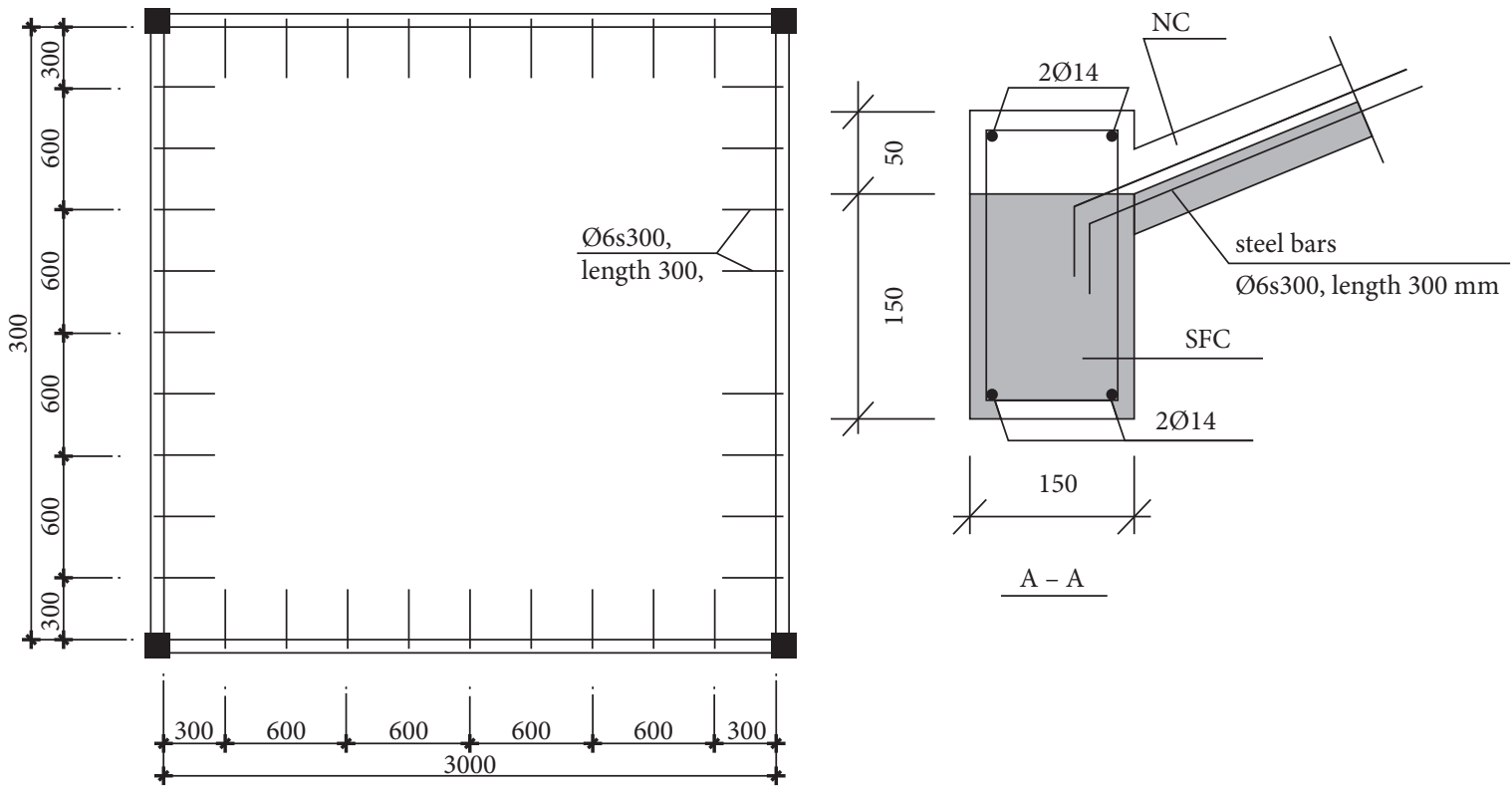

(b)

(c)

FIGURE 1: Doubly curved shell with double-layer, $3000 \times 3000 \mathrm{~mm}$. (a) Doubly curved shell model, (b) plan of steel bars connected between the shell and curved beams, and (c) A-A section.

The results of vertical displacements and stresses in the 3 investigated cases are shown in Figure 14.

Vertical displacement and stresses values are presented in Table 4.

Discussion of Result. In Figure 14 and Table 4,

(i) Case 1 and Case 3: the total thickness is equal but the SFCL is larger, and the vertical displacement and stresses are smaller in the 3 investigated cases. In Figure 14(a), the thickness of the SFCL is increased, and the vertical displacement is reduced; that is, the larger the thickness of the SFCL is, the better the shell works.

(ii) The stage where the concrete cracks appear: in Case 3 , the underlying SFCL is thicker, so the cracks appear more slowly. In Case 2 (minimum 


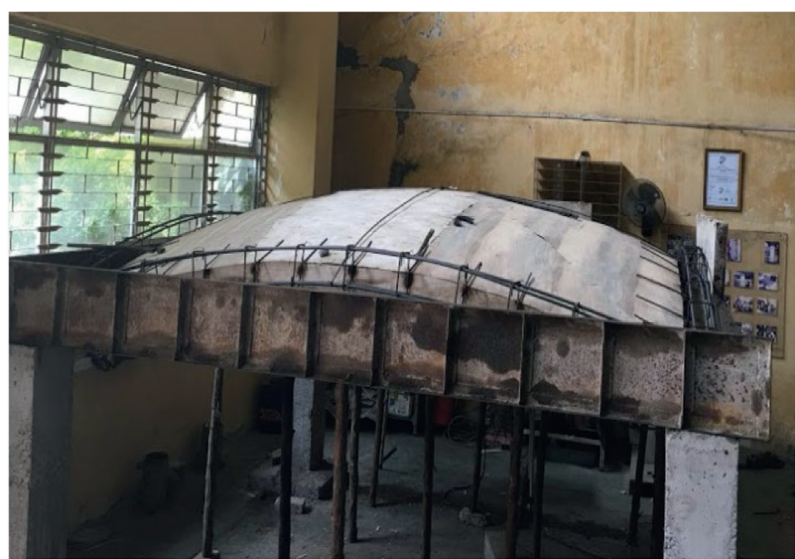

(a)

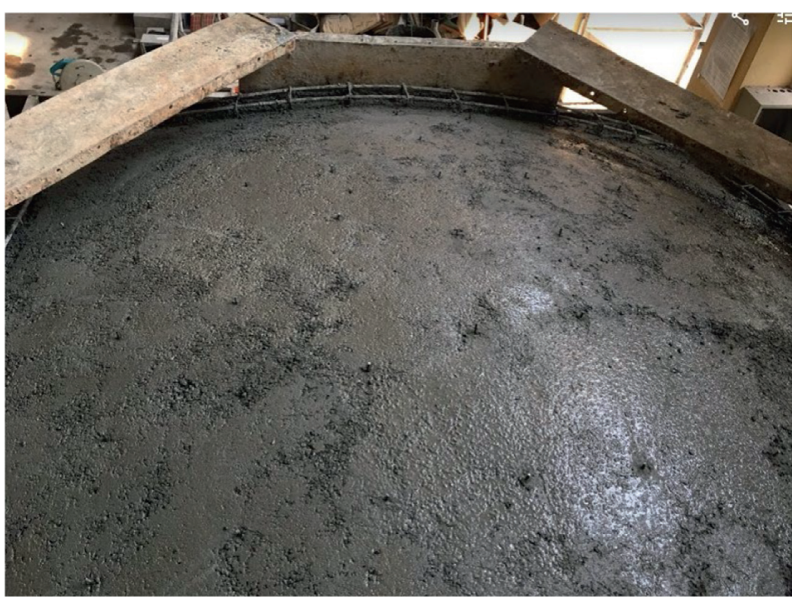

(b)

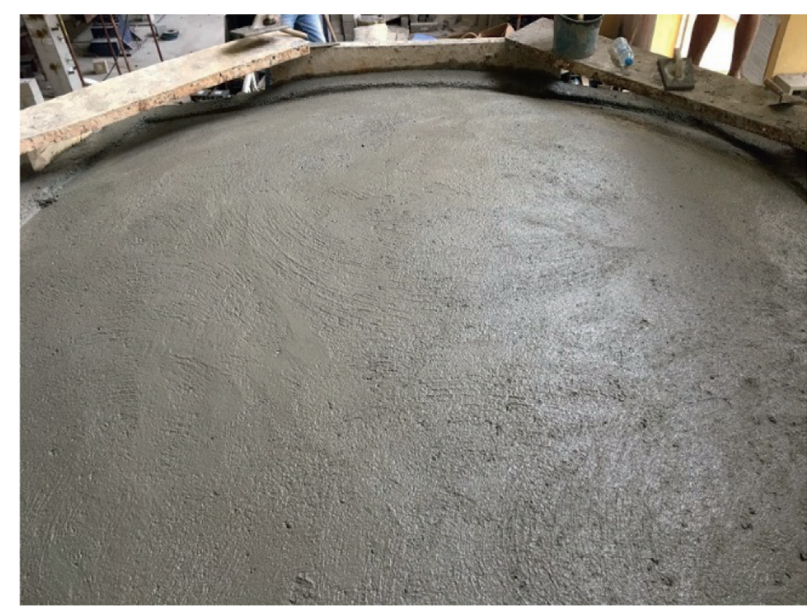

(c)

FIGURE 2: Making the formwork and pouring concrete layers: (a) make the formwork, (b) the first layer of steel fibres concrete was poured, and (c) the normal concrete layer is poured last.

thickness), cracks appear earlier than in other cases. That is, the underlying SFCL will resist the appearance of cracks in the shell when the load is increased.

(iii) The research results show that the cracks in the three investigated cases are in the SFCL below it. That is, at the shell boundary, the lower layer of concrete is tensile, while the upper layer of normal concrete is compressive.

3.3. Investigate the Effect of the Location of the SFCL. The use of an SFCL under an NCL was studied. The SFCL is put on top of the NCL in other cases (such as when fixing the shell roof s surface). This study conducted two experiments to see how the location of the SFCL influences the state of stress and strain of the shell; the SFCL is located above and below the NCL, with the thickness of the layers in the shell being the same, as presented in Table 5.

The results of vertical displacements and stresses are shown in Figure 15.
Vertical displacement and stresses values are presented in Table 6

Discussion of Result.

In Figure 15 and Table 6, the concrete begins to show cracks; in Case 4 , load $P=11.5 \mathrm{kN} / \mathrm{m}^{2}$, stress is $102.7 \mathrm{~N} / \mathrm{cm}^{2}$, the first cracks appear in the shell along the boundary of the lower NCL, and the maximum vertical displacement at the top of the shell is $0.174 \mathrm{~mm}$, while in Case 2, it is $P=12.5 \mathrm{kN} / \mathrm{m}^{2}$; this means that the SFCL below NCL will crack later than it does on top, and in both Case 2 and Case 4, the concrete layer below will be cracked first.

When the SFCL is located in the compression zone of the shell, the stress $\sigma_{x}$ near the shell boundary is reduced by $15 \%$, and the stress $\sigma_{y}$ is reduced by $52 \%$. The results of this study show that the lower layer is the tensile layer, and the upper layer is compressive. Therefore, strengthening the SFCL located in the tensile zone will be more effective when it is located above.

3.4. Investigate the Influence of the Percentage of Steel Fibres Contained in Concrete. In Table 3, the percentage of steel 


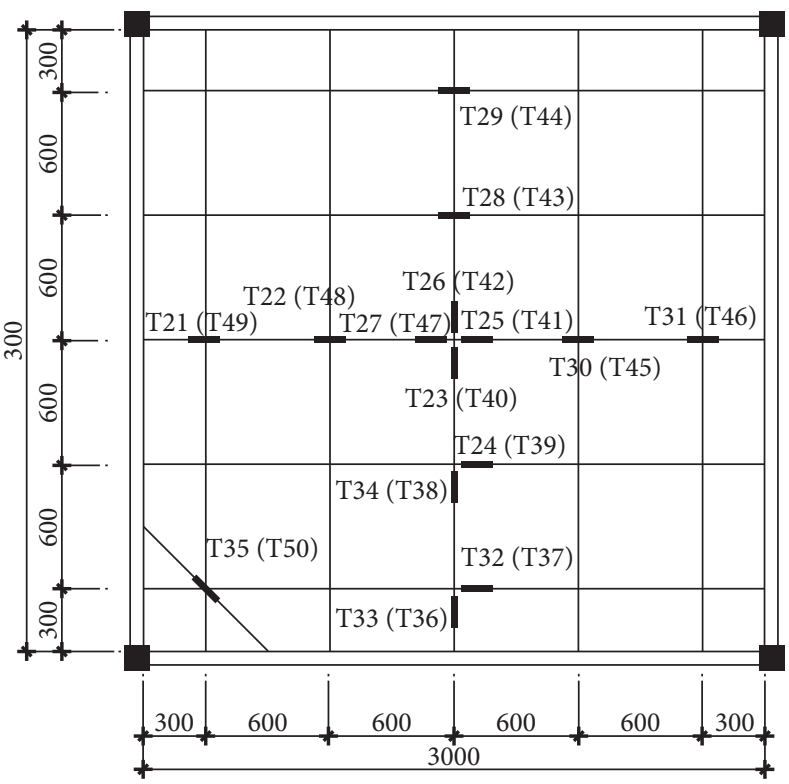

(a)

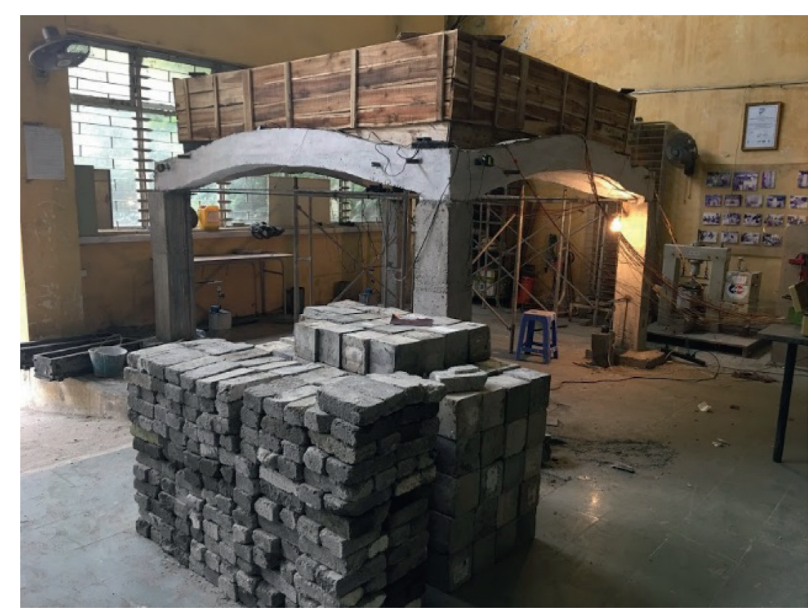

(c)

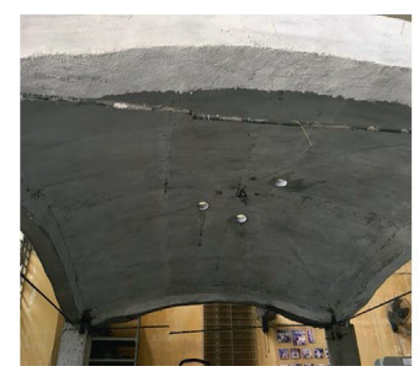

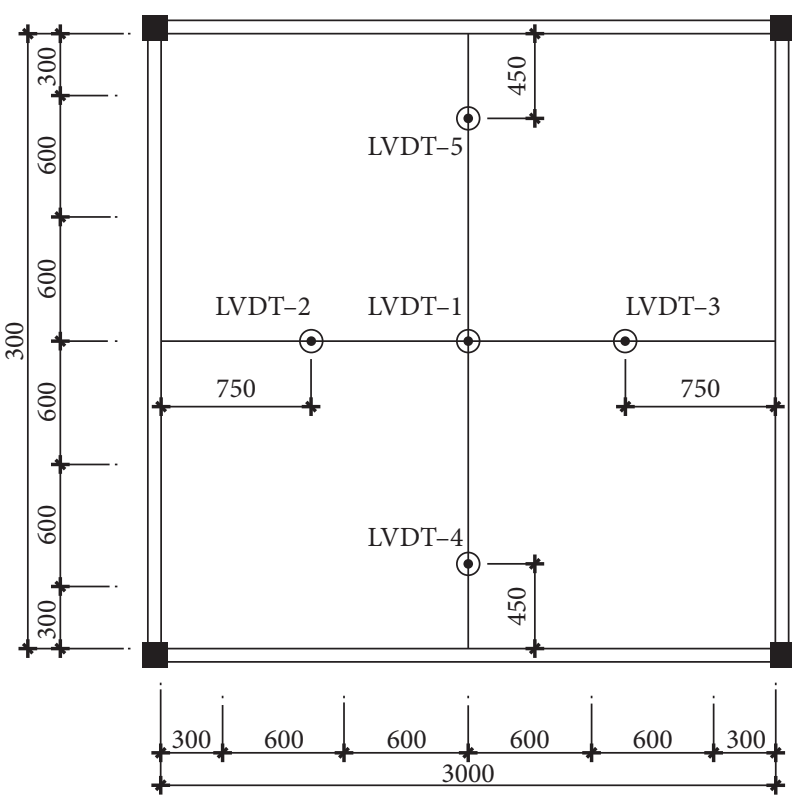

(b)

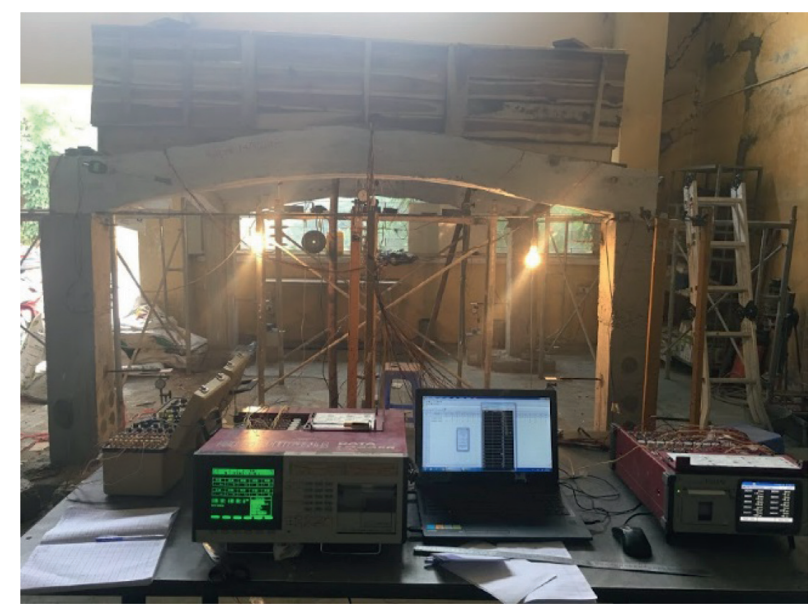

(d)

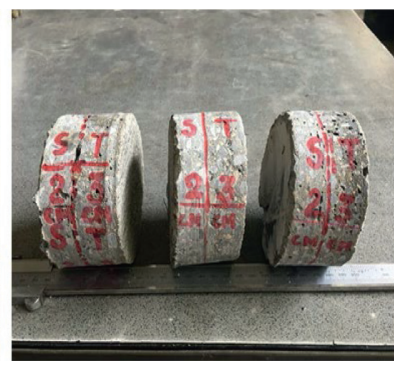

(e)

FIGURE 3: Installation of measuring equipment and loading on the shell. (a) Installation diagram of strain gauges (tensiometers). (b) Installation diagram of LVDTs. (c) Load the shell with small concrete blocks. (d) Connect the measuring equipment to the computers. (e) Check the thickness of the layers.

fibres contained in concrete is $2 \%$, and here it is changed to $0 \%$ and $3 \%$ for all 4 investigated cases .

Case 1. This study investigates the change of the percentage of steel fibres contained in concrete, $0 \%, 2 \%$, and $3 \%$, as shown in Figure 16:
Discussion of Result.

Direction of movement of the layers in the shell: the upper layer displaces towards the center, while the lower layer is directed away from the center of the shell when the shell is under load (Figure 16(b)). 


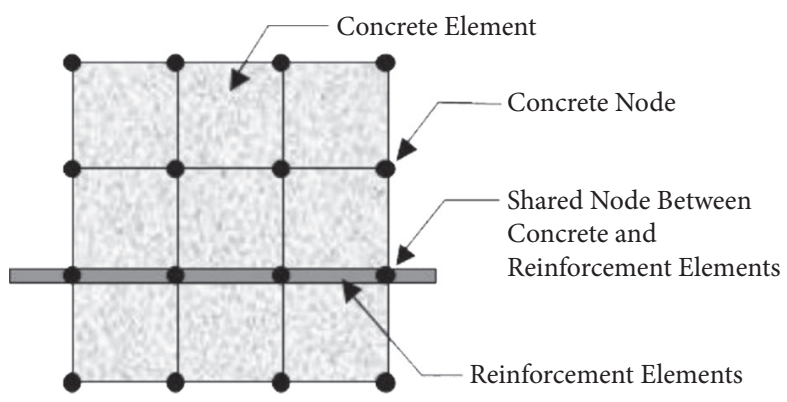

(a)

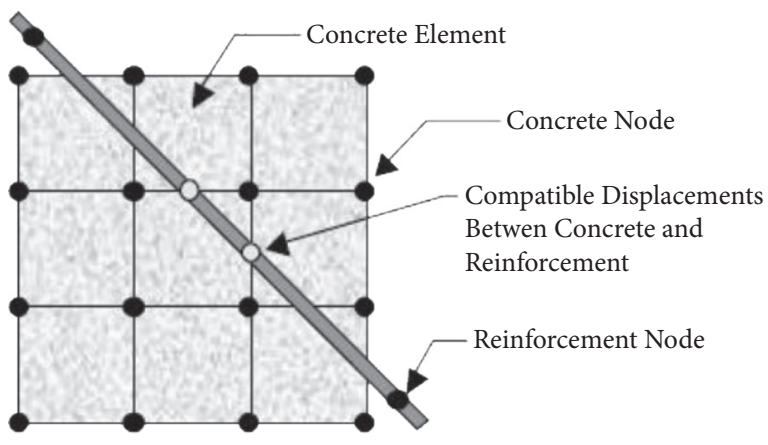

(b)

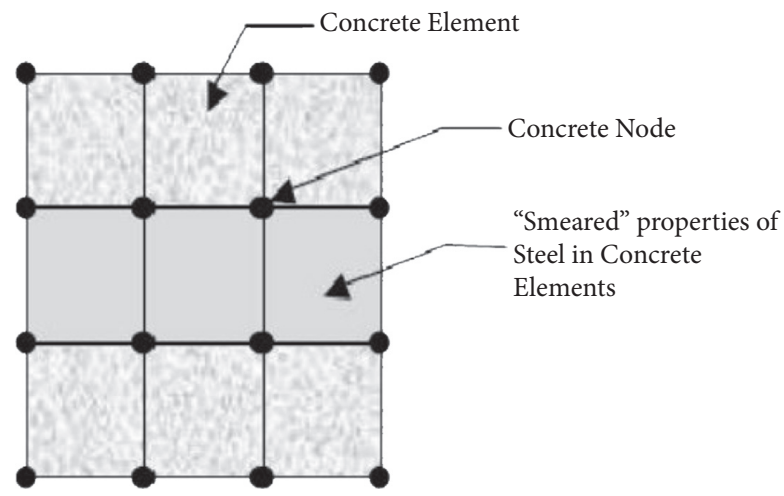

(c)

Figure 4: Steel fibres' models [31]: (a) smeared model, (b) embedded model, and (c) discrete model.

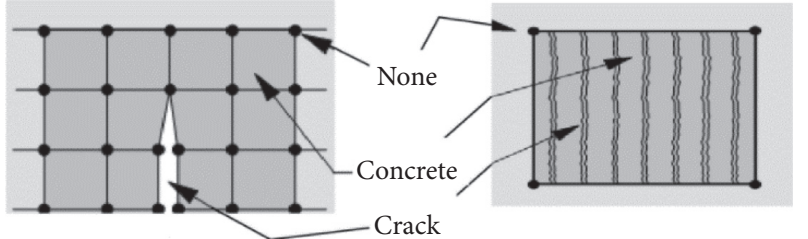

(a)

(b)

Figure 5: Concrete cracking model [31]: (a) discrete and (b) smeared.

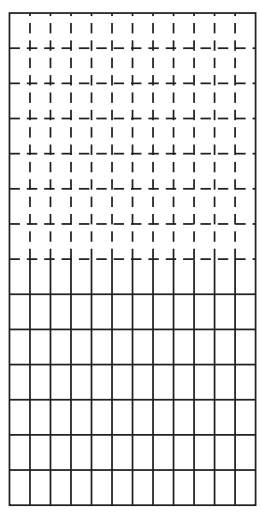

(a)

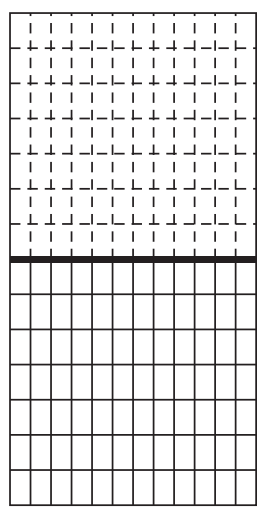

(b)

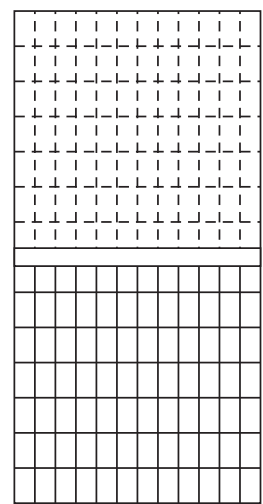

(c)

Figure 6: Three contact models: (a) continuous model, (b) interface model, and (c) thin-layer model. 


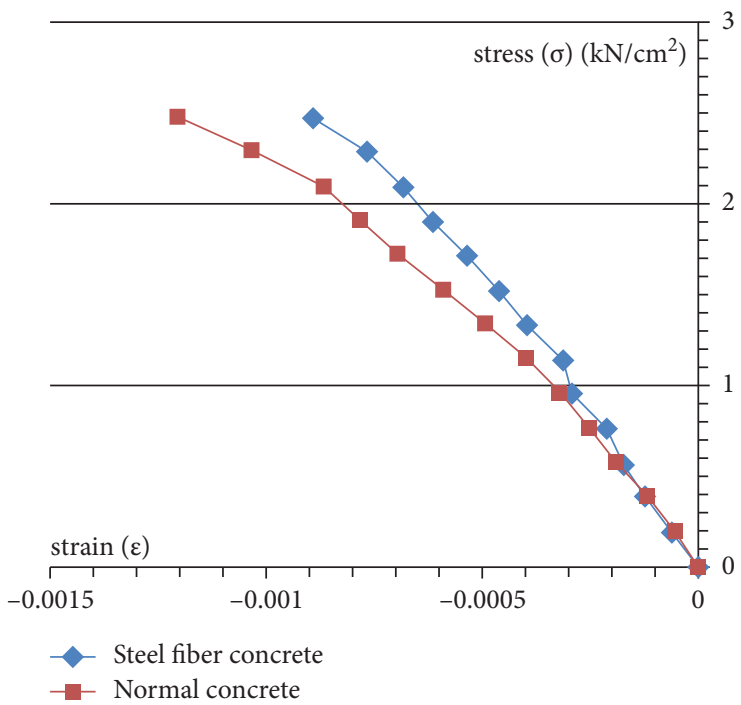

FIgURE 7: Stress-strain relationship of the two types of concrete.

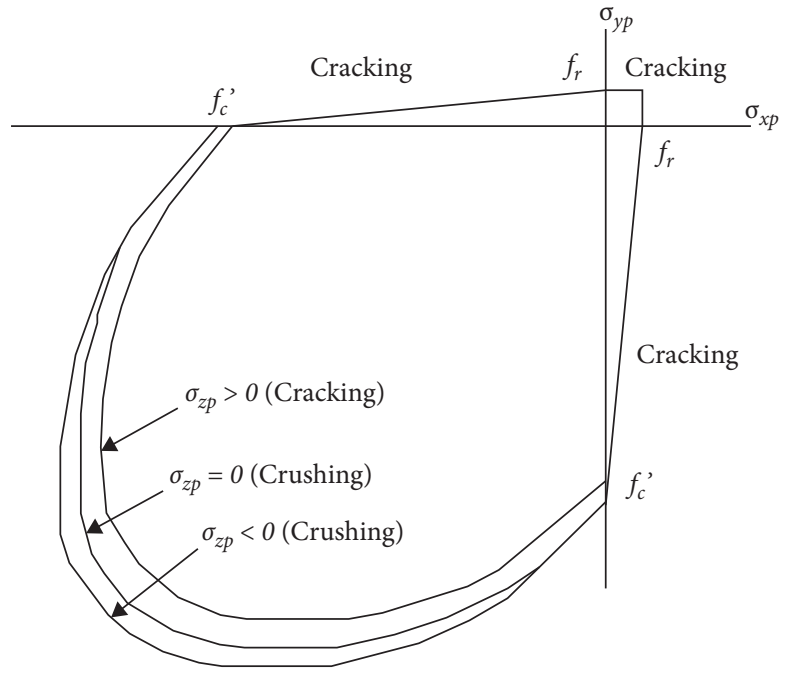

FIGURE 8: Failure Surface for concrete [31].

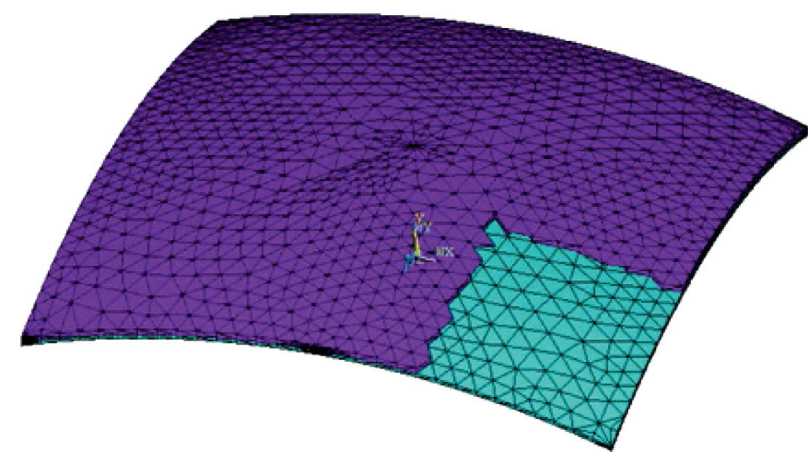

(a)

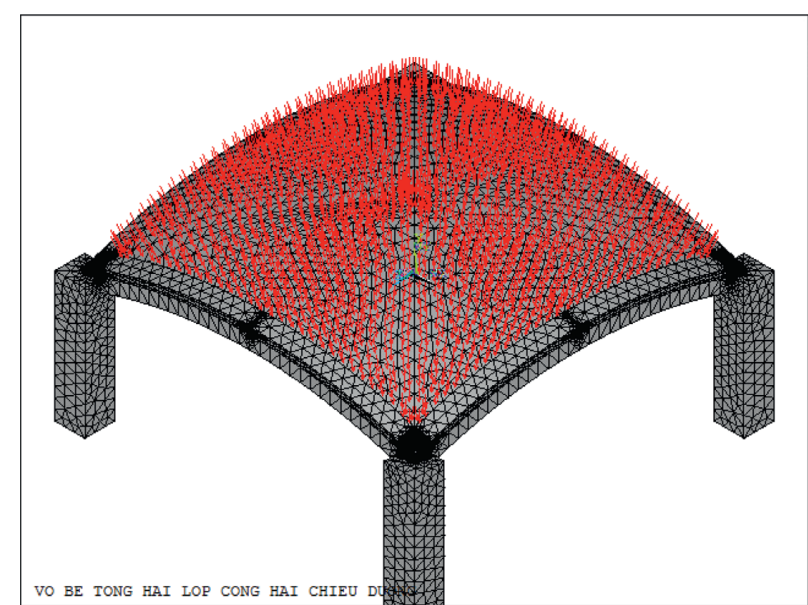

(b)

FIgURE 9: Meshing, boundary of shell, and load. (a) Meshing of elements; (b) boundary of shell and load. 


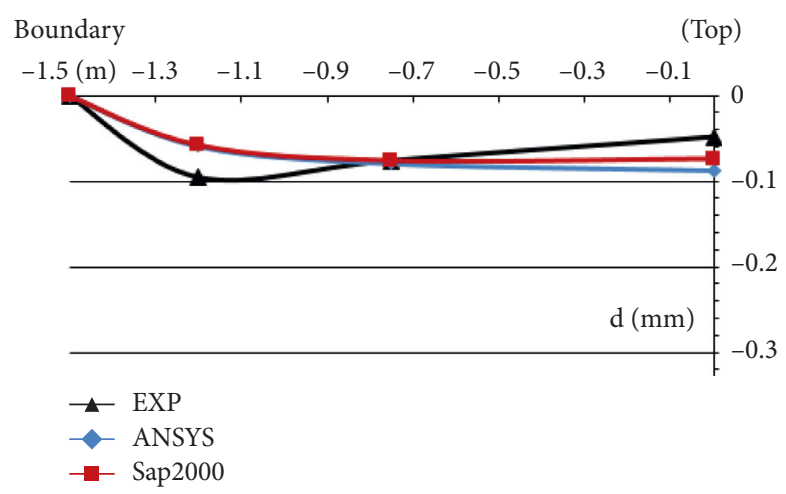

Figure 10: Load and vertical displacement in methods.

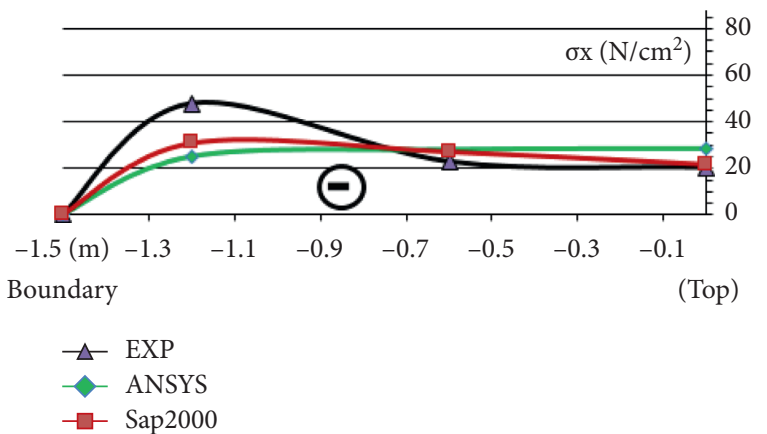

(a)

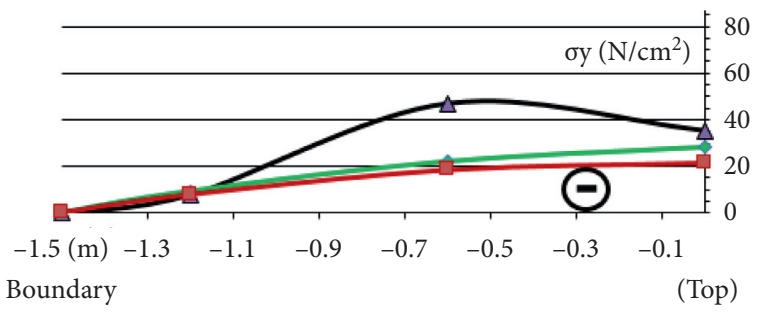

$\triangle$ EXP
$\neg$ ANSYS
$\neg$ Sap2000

(b)

FIgURE 11: Stresses in the methods: (a) stress $\sigma_{x}$ in the methods; (b) stress $\sigma_{y}$ in the methods.

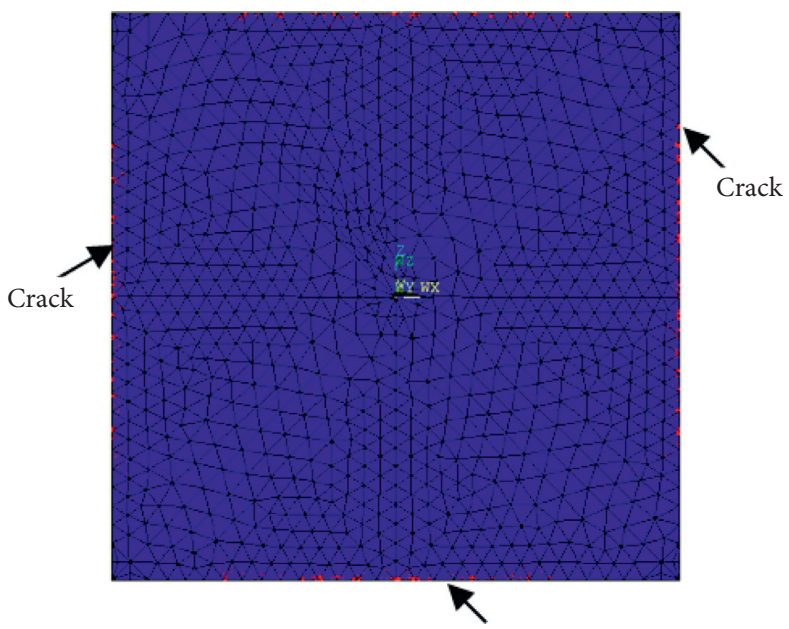

VO BE TONG HAI LOP CONG HAI CHIEU DUONG

FIgURE 12: Location of cracks in shell (Case 1).

In Figure 16(c), the change of vertical displacement value is $0.05 \mathrm{~mm}$, and this value is very small and considered the same.

Stress in the $x$ and $y$ directions (Figures 16(d), and $16(\mathrm{e}))$ : these stresses are the same for the percentage of steel fibres in concrete $0 \%$ and $3 \%$ and vary from $9 \mathrm{~N} / \mathrm{cm}^{2}$ to $13 \mathrm{~N} / \mathrm{cm}^{2}$ when the percentage of steel fibres is $2 \%$. Not using this percentage of steel fibres or using so much the percentage of steel fibres in concrete is inefficient and counterproductive, that is, 3\% steel 


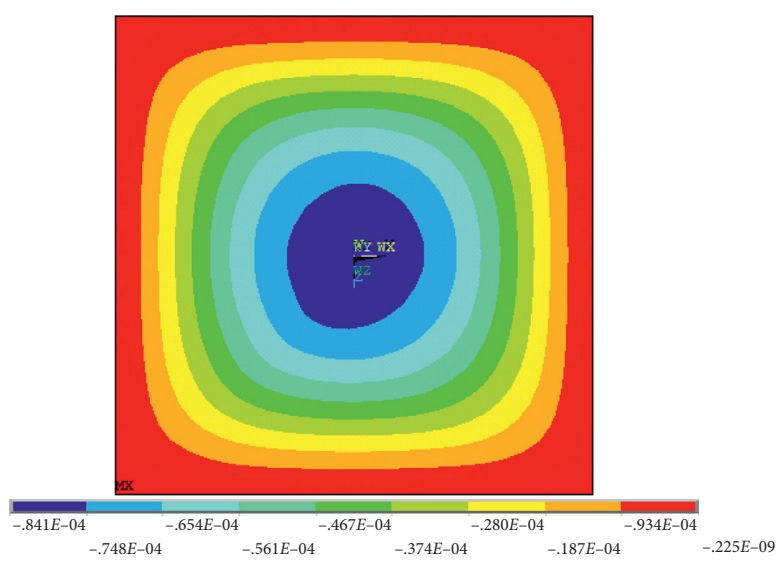

VO BE TONG HAI LOP CONG HAI CHIEU DUONG

(a)

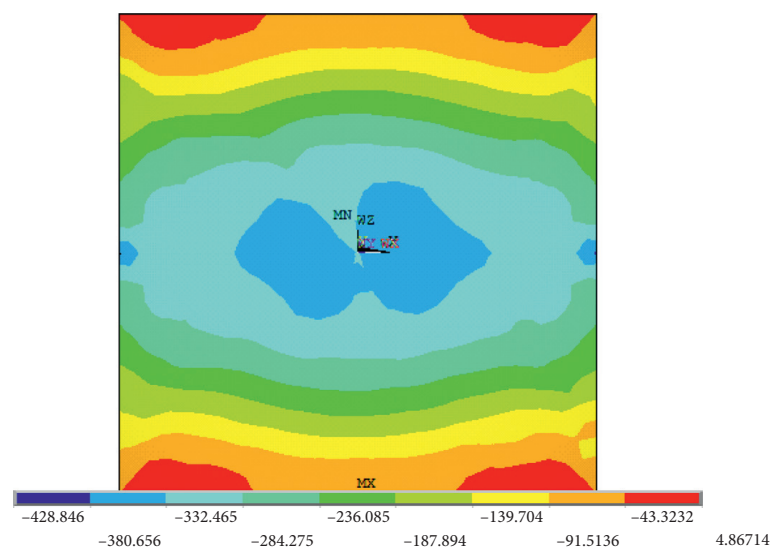

VO BE TONG HAI LOP CONG HAI CHIEU DUONG

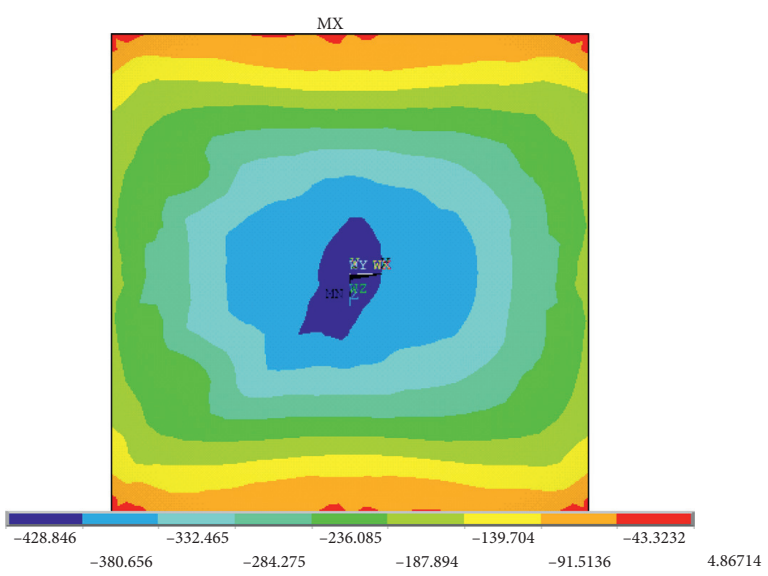

VO BE TONG HAI LOP CONG HAI CHIEU DUONG

(b)

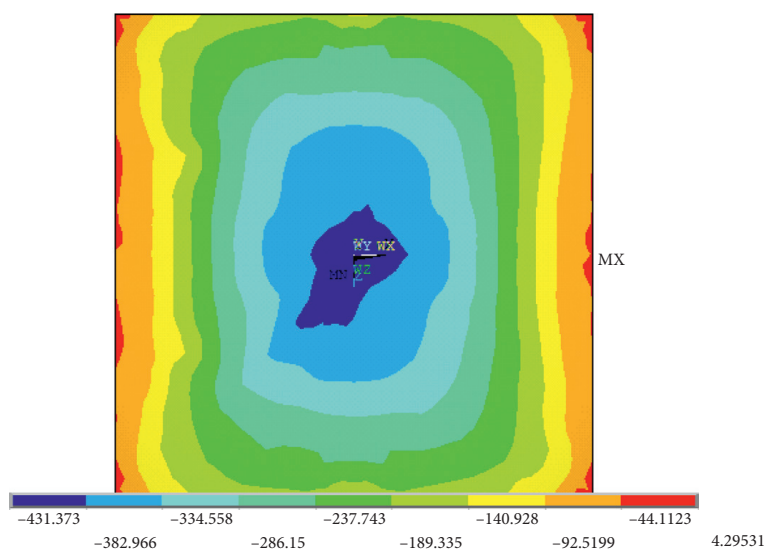

VO BE TONG HAI LOP CONG HAI CHIEU DUONG

(c)

(d)

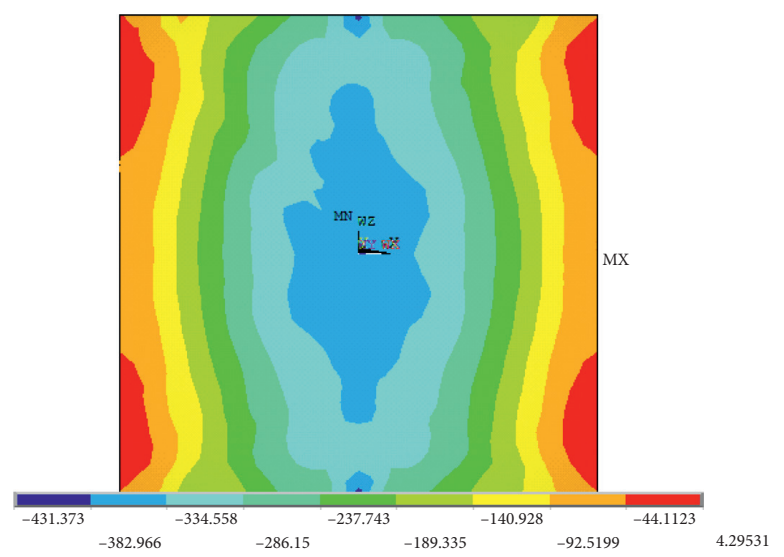

VO BE TONG HAI LOP CONG HAI CHIEU DUONG

(e)

Figure 13: Vertical displacement and stresses (Case 2): (a) vertical displacement in shell; (b) stress $\sigma_{x}$ of top surface in shell; (c) stress $\sigma_{x}$ of bottom surface in shell; (d) stress $\sigma_{y}$ of top surface in shell; (e) stress $\sigma_{y}$ of bottom surface in shell.

TABLE 3: Thickness of layers with the following 3 cases studied.

\begin{tabular}{lccc}
\hline & Case 1 & Case 2 & Case 3 \\
\hline$h_{1}+h_{2}(\mathrm{~cm})$ & $2+3$ & $2+2$ & $3+2$ \\
\hline
\end{tabular}




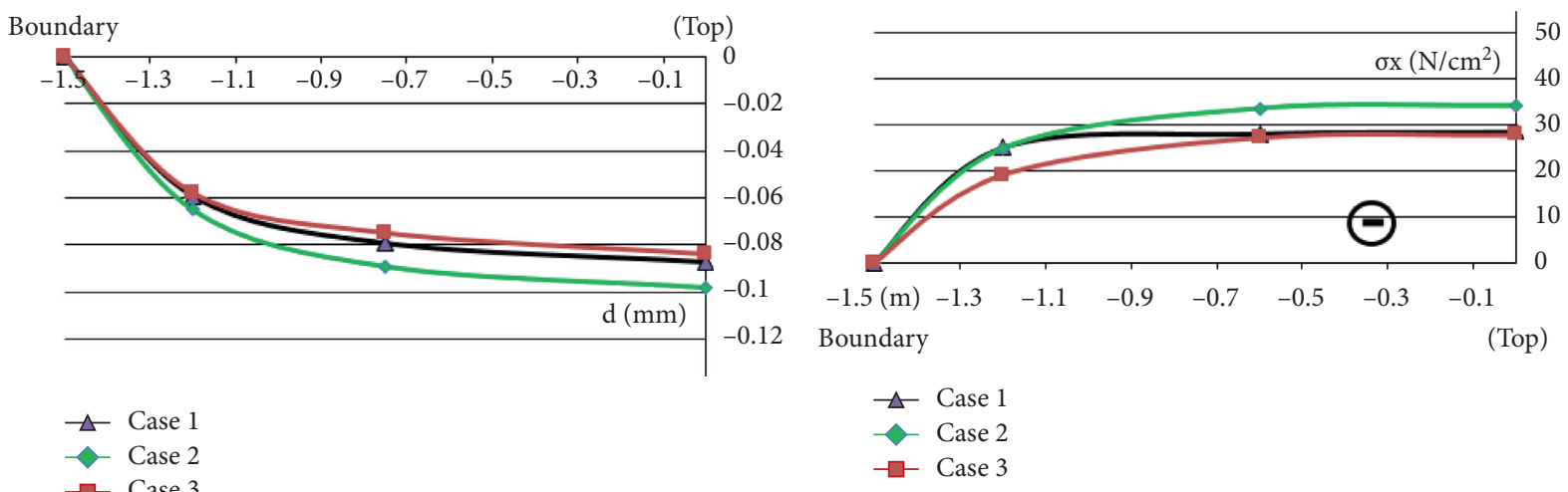

(a)

(b)

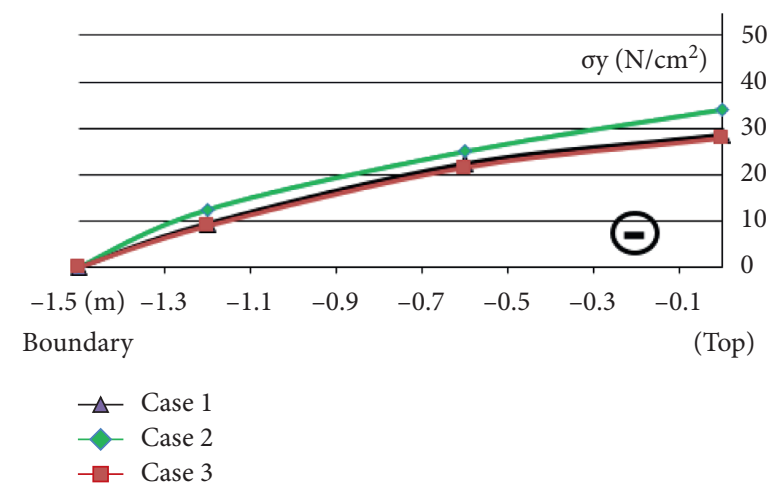

(c)

Figure 14: Vertical displacement and stresses in 3 investigated cases: (a) vertical displacement of shell in 3 investigated cases; (b) stress $\sigma_{x}$ of shell in 3 investigated cases; (c) stress $\sigma_{y}$ of shell in 3 investigated cases.

TABLE 4: Vertical displacement and stresses values.

(a) Vertical displacement in 3 investigated cases Location

$\begin{array}{ll}(\mathrm{m}) & \text { Case 1 } \\ 0 & -0.071 \\ 0.75 & -0.063 \\ 1.1 & -0.039 \\ 1.5 & \end{array}$

1.5

0

(b) Stresses in 3 investigated cases Location

\begin{tabular}{lc}
$(\mathrm{m})$ & Case 1 \\
0 & -37.1 \\
0.6 & -32.7 \\
1.2 & -23.9 \\
1.5 & 0 \\
\hline
\end{tabular}

Vertical displacement $(\mathrm{mm})$

$\begin{array}{ll}\text { Case } 2 & \text { Case } 3 \\ -0.084 & -0.069 \\ -0.074 & -0.054 \\ -0.047 & -0.031\end{array}$

0

$\begin{array}{cc}\text { Stress } \sigma_{y}\left(\mathrm{~N} / \mathrm{cm}^{2}\right) & \\ \text { Case } 2 & \text { Case } 3 \\ -43.1 & -36.5 \\ -38.3 & -31.1 \\ -14 & -9.3 \\ 0 & 0\end{array}$

TABLE 5: Location of the SFCL.

\begin{tabular}{lcr}
\hline & Case 2 (SFCL on bottom) & Case 4 (SFCL on top) \\
\hline$h_{1}+h_{2}(\mathrm{~cm})$ & $2+2(\mathrm{~cm})$ & $2+2(\mathrm{~cm})$ \\
\hline
\end{tabular}

fibres that has surpassed the limit of the percentage of steel fibres in concrete [35].

Case 2. This study investigates the change of the percentage of steel fibres in concrete, $0 \%, 2 \%$, and $3 \%$, as shown in Figure 17:
Discussion of Result.

In Figure 17, similar to Case 1, vertical displacement and stresses $\sigma_{x}$ and $\sigma_{y}$ with $2 \%$ the percentage of steel fibres are the most optimal percentage of the studied percentage of steel fibres. The vertical displacement at 


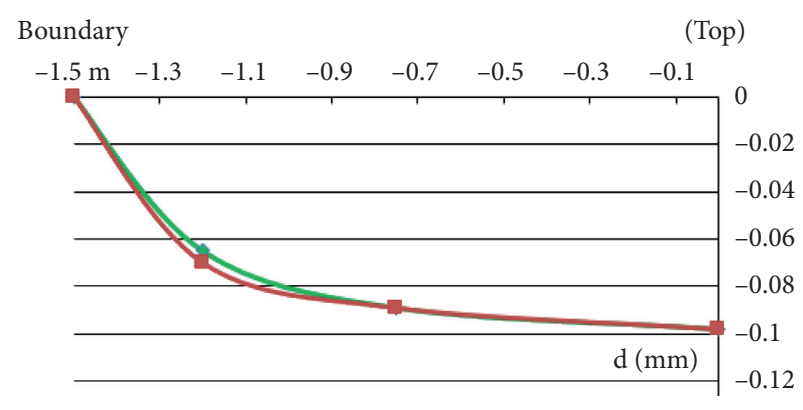

Case 2

- Case 4

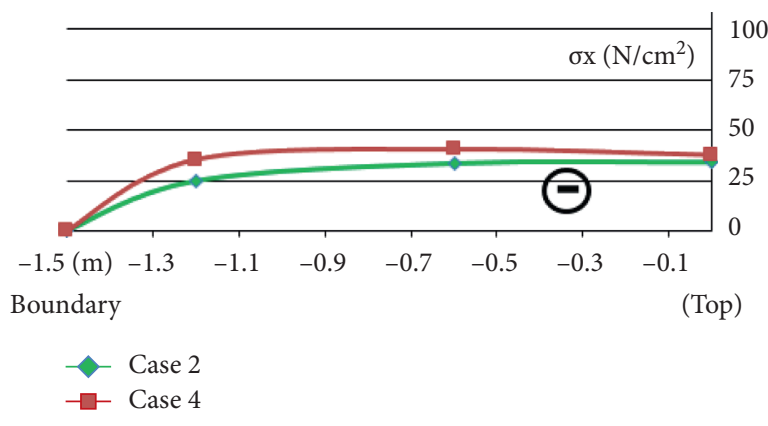

(b)

(a)

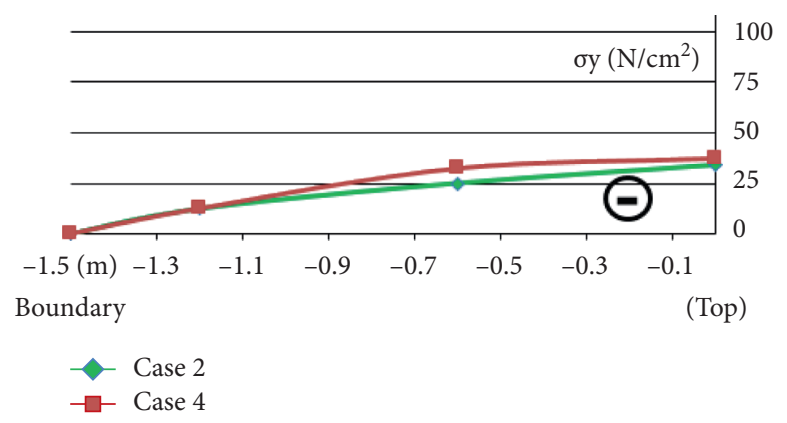

(c)

Figure 15: Vertical displacement and stresses in Case 2 and Case 4: (a) vertical displacement of shell in Case 2 and Case 4; (b) stress $\sigma_{x}$ of shell in Case 2 and Case 4; (c) stress $\sigma_{y}$ of shell in Case 2 and Case 4.

TABLE 6: Vertical displacement and stresses values in cases.

(a) Vertical displacement in Case 2 and Case 4

\section{Location}

$\begin{array}{lc}(\mathrm{m}) & \text { Case } 2 \\ 0 & -0.084 \\ 0.75 & -0.074 \\ 1.1 & -0.047 \\ 1.5 & 0\end{array}$

Vertical displacement ( $\mathrm{mm})$

$\begin{array}{cc}\text { Case } 4 & \text { Difference }(\%) \\ -0.084 & 0 \\ -0.075 & 1.35 \\ -0.048 & 2.13 \\ 0 & 0\end{array}$

(b) Stresses in Case 2 and Case 4

\begin{tabular}{lccc} 
Location & & Stress $\sigma_{x}\left(\mathrm{~N} / \mathrm{cm}^{2}\right)$ & \\
$(\mathrm{m})$ & Case 2 & Case 4 & Difference (\%) \\
0 & -42.8 & -49.7 & 16.12 \\
0.6 & -38.1 & -44.1 & 15.75 \\
1.2 & -28.4 & -32.8 & 15.49 \\
1.5 & 0 & 0 & 0 \\
\hline
\end{tabular}

\begin{tabular}{ccc} 
& Stress $\sigma_{y}\left(\mathrm{~N} / \mathrm{cm}^{2}\right)$ & \\
Case 2 & Case 4 & Difference $(\%)$ \\
-43.1 & -49.1 & 13.92 \\
-38.3 & -43.6 & 13.84 \\
-14.0 & -21.3 & 52.14 \\
0 & 0 & 0 \\
\hline
\end{tabular}

the percentage of steel fibres in concrete is $2 \%$, from $0 \%$ to $3 \%$ of $0.05 \mathrm{~mm}$, which is very small and is considered unaffected. There is also the stress difference in the directions from 10 to $13 \mathrm{~N} / \mathrm{cm}^{2}$ at the location near the shell boundary and at the top of the shell.

The two analyzed cases (Case 1 and Case 2) showed that the locations near the boundary and at the top of the shell are the locations that will be sensitive to the load. When designing this shell, attention should be paid to these 2 locations.
Case 3. This study investigates the change of the percentage of steel fibres in concrete, $0 \%, 2 \%$, and $3 \%$, as shown in Figure 18.

Discussion of Result. In Figures 16-18, all 3 cases (Case1, Case 2, and Case 3) have the largest vertical displacement value at the top of the shell, and the difference is $0.9 \mathrm{~mm}$. Stresses $\sigma_{x}$ and $\sigma_{y}$ are also the highest at the top of the shell and range from 29 to $39 \mathrm{~N} / \mathrm{cm}^{2}$. Among the percentage of steel fibres in concrete, the $2 \%$ steel fibres content is still the most 


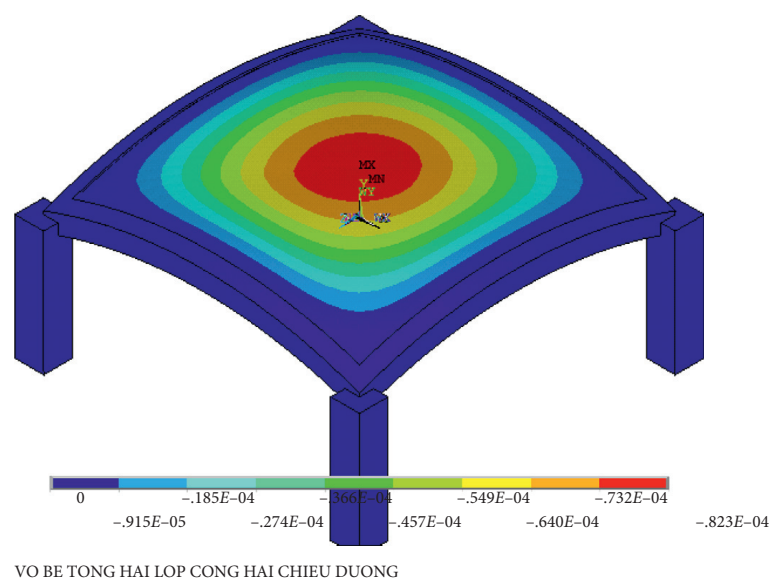

(a)

Boundary

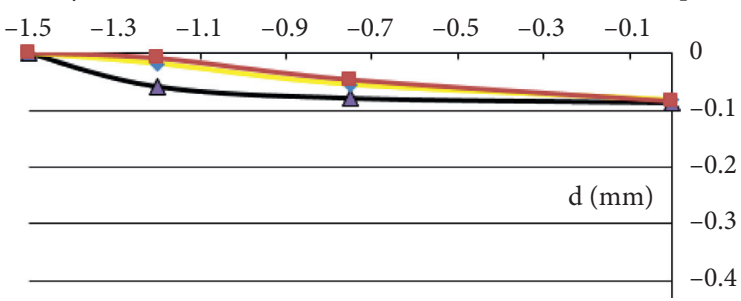

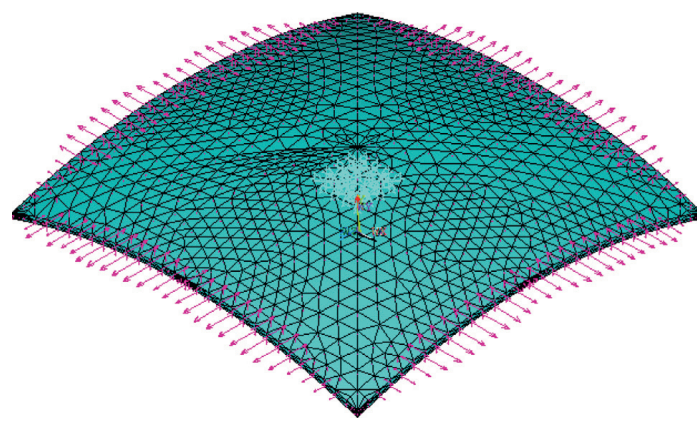

VO BE TONG HAI LOP CONG HAI CHIEU DUONC

(b)

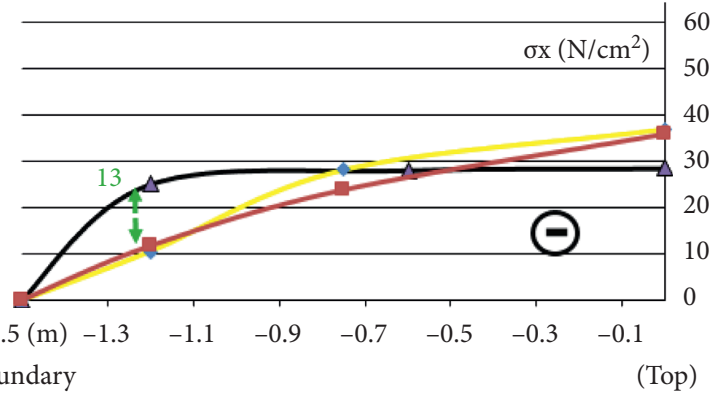

$\triangle$ Case $1-2 \%$

- Case 1-3\%

-n- Case 1-0\%

(d)

(c)

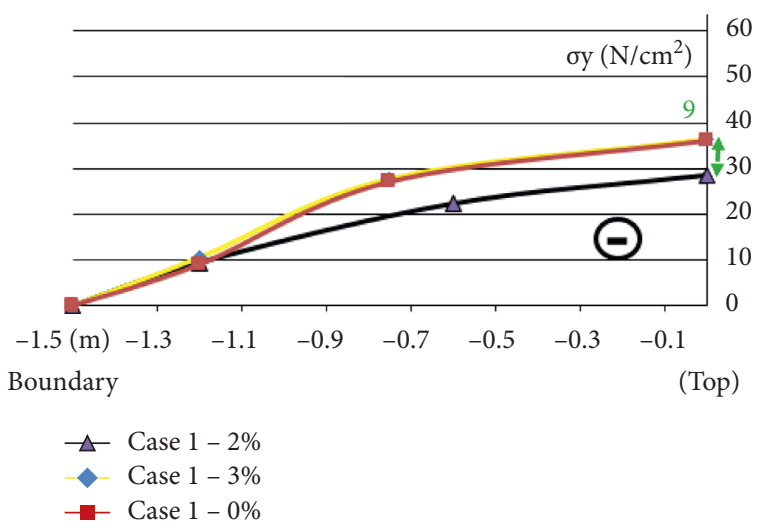

(e)

Figure 16: The change of percentage of steel fibres in concrete (Case 1). (a) Spectrum of vertical displacement in the shell; (b) the direction of movement of each layer; (c) vertical displacement of the shell; (d) stress $\sigma_{x}$ of shell; (e) stress $\sigma_{y}$ of shell.

optimal in all the investigated cases. The locations near the boundary and top of the shell are locations that are very sensitive to the load.

Case 4 . This study investigates the percentage of steel fibres in concrete, $0 \%, 2 \%$, and $3 \%$, as shown in Figure 19.
Discussion of Result. In Figure 19, the vertical displacement of the shell is similar to the three cases above where the SFCL is placed on top of NCL. However, the stress values $\sigma_{x}$ and $\sigma_{y}$ start to change in the direction of increasing the stress value, and the stress at the top of the shell increases from 39 to $50 \mathrm{~N} / \mathrm{cm}^{2}$. The percentage 

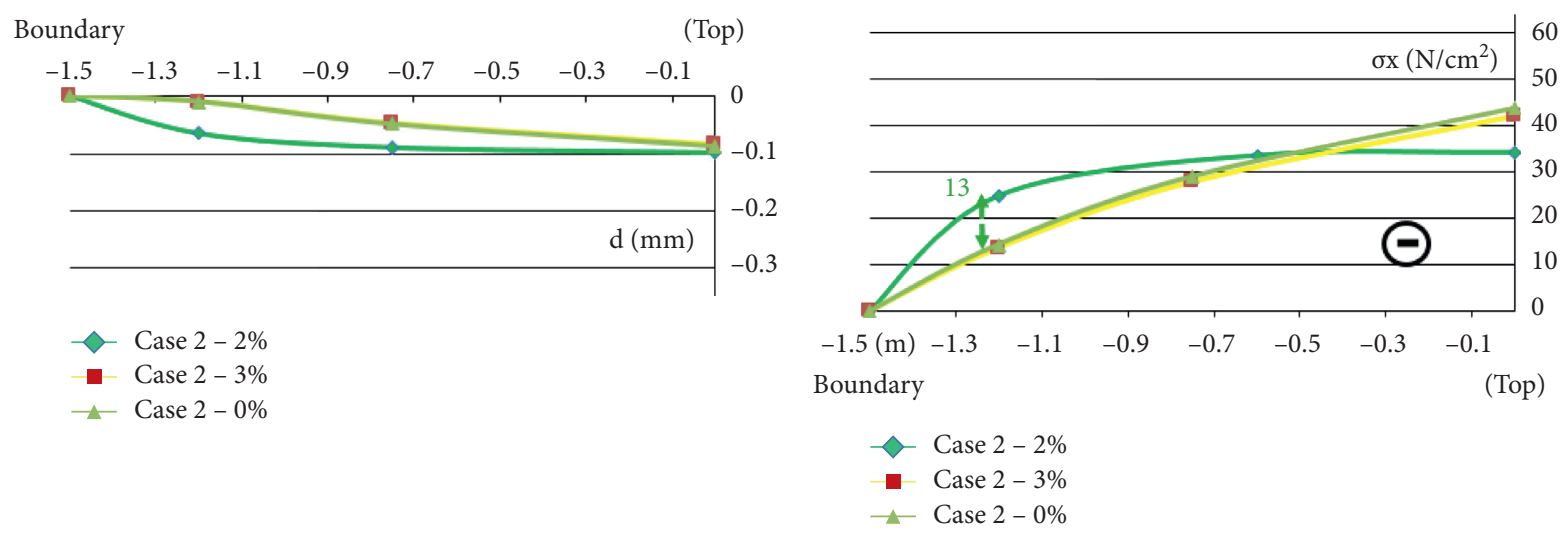

(a)

(b)

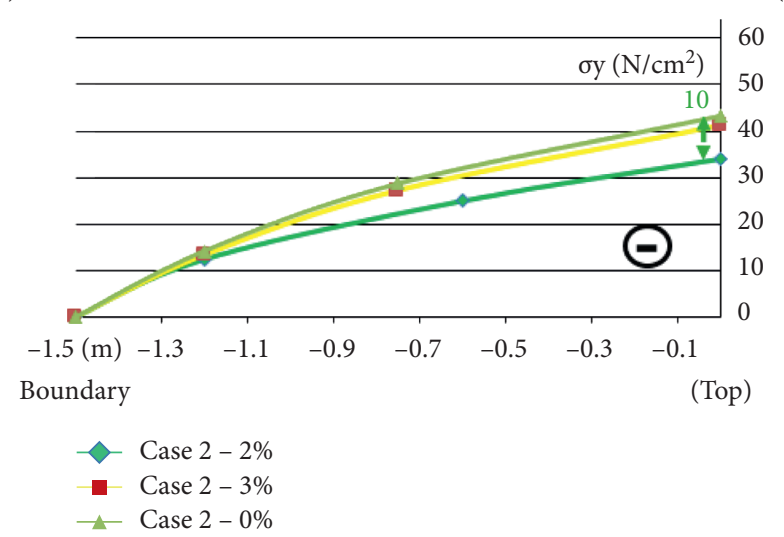

(c)

FIgURE 17: The change of percentage of steel fibres in concrete (Case 2): (a) vertical displacement of the shell; (b) stress $\sigma_{x}$ of shell; (c) stress $\sigma_{y}$ of shell.

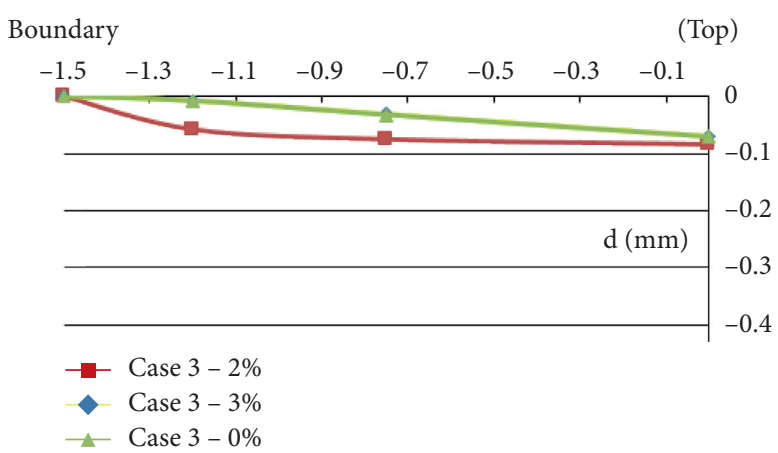

(a)

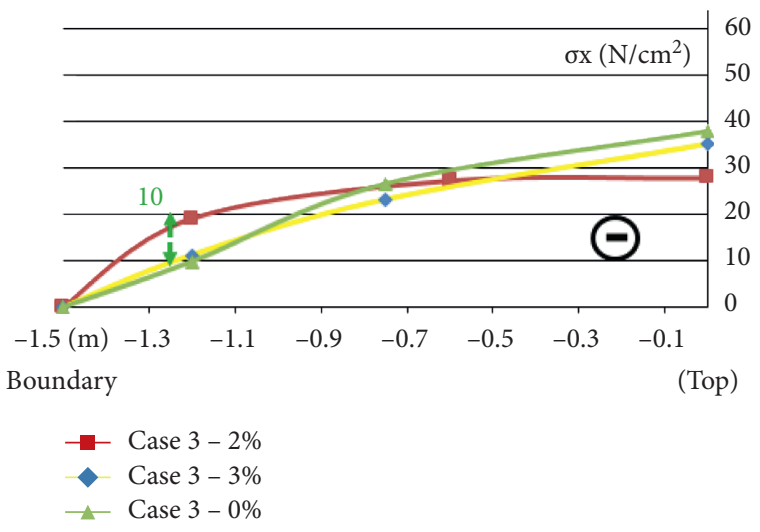

(b)

FIgURE 18: Continued. 


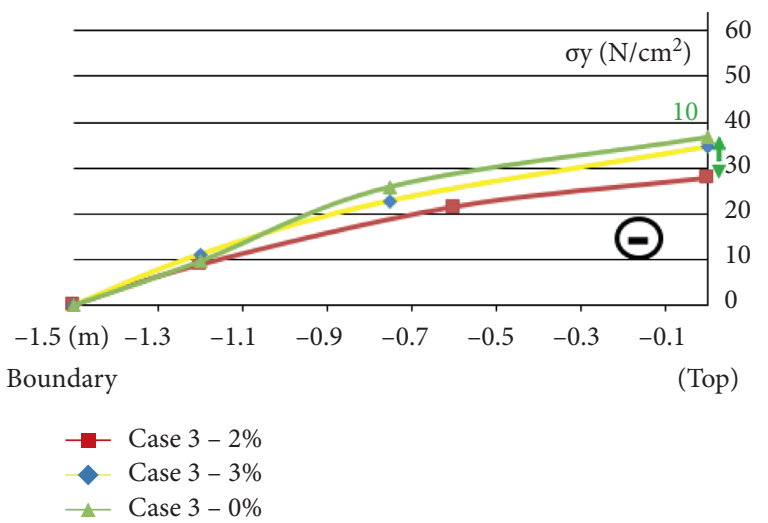

(c)

Figure 18: The change of percentage of steel fibres in concrete (Case 3): (a) vertical displacement of the shell; (b) stress $\sigma_{x}$ of shell; (c) stress $\sigma_{y}$ of shell.

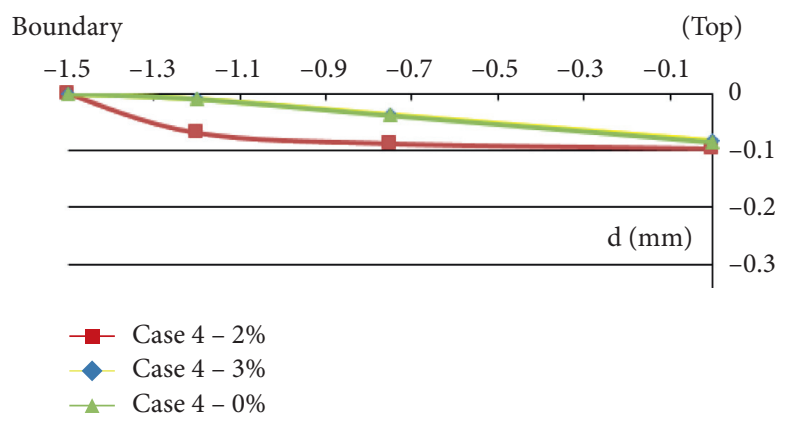

(a)

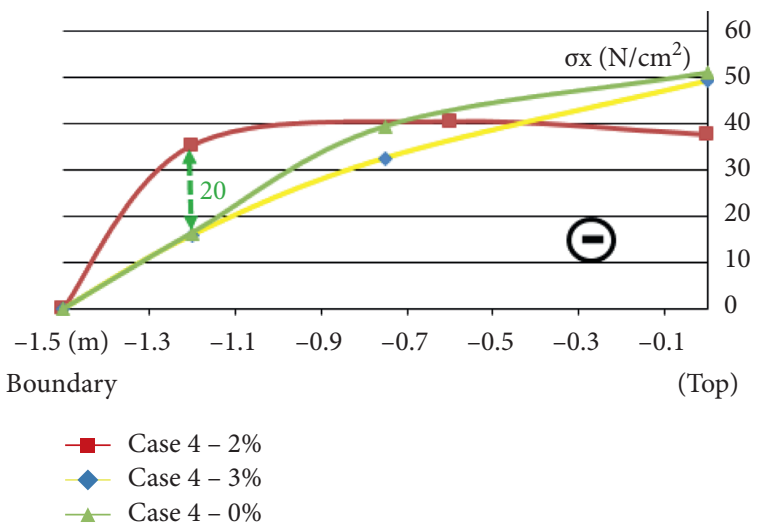

(b)

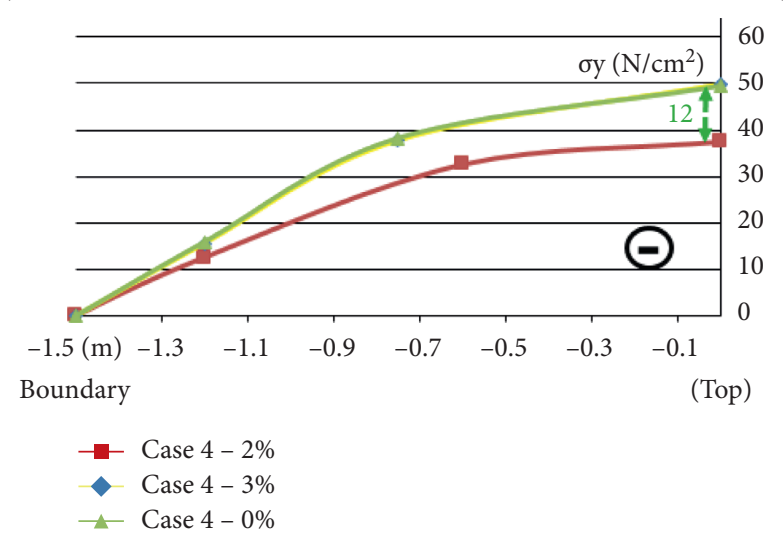

(c)

Figure 19: The change of percentage of steel fibres in concrete (Case 4): (a) vertical displacement of the shell; (b) stress $\sigma_{x}$ of shell; (c) stress $\sigma_{y}$ of shell.

of steel fibres in concrete with $2 \%$ is still the most optimal in all cases; however, the difference in stress between $2 \%, 0 \%$, and $3 \%$ is 12 to $20 \mathrm{~N} / \mathrm{cm}^{2}$. The 4 cases that have been investigated show that the above SFCL will make the shell increase the stresses values in the directions.

\section{Conclusion}

The results of the study lead to the following conclusions:

(1) Research results of vertical displacement and stresses $\sigma_{x}$ and $\sigma_{y}$ in all 3 methods, experimental, ANSYS 
simulation, and Sap2000 with similar shapes: however, the experimental results are affected by boundary conditions, material homogeneity, and so on, further research is needed at the location from $0.6 \mathrm{~m}$ to $1.2 \mathrm{~m}$ to clarify these difference values. However, these difference values are not large and can be accepted in this study.

(2) The influence of the thickness of the layers shows that the thickness of the SFCL is increased, and the vertical displacement is reduced; that is, the larger the thickness of the SFCL, the better the shell works. At the shell boundary, the lower layer of concrete is tensile, while the upper layer of NC is compressive.

(3) The influence of the location of the SFCL in the shell: the first cracks appear in the shell along the boundary of the lower NCL, and the SFCL below NCL will crack later than it does on top, and in both Case 2 and Case 4, the concrete layer below will be cracked first. Therefore, strengthening the SFCL located in the tensile zone will be more effective when it is located above.

(4) The influence of the percentage of steel fibres in concrete: not using this percentage of steel fibres, or using so much the percentage of steel fibres in concrete is inefficient and counterproductive. Among the percentage of steel fibres in concrete, the $2 \%$ steel fibres content is still the most optimal in all the investigated cases. The locations near the boundary and top of the shell are locations that are very sensitive to the load. The 4 cases that have been investigated show that the above SFCL will make the shell increase the stresses values in the directions.

\section{Abbreviations}

FE: Finite element

NC: Normal concrete

NCL: Normal concrete layer

SFC: Steel fibre concrete

SFCL: Steel fibre concrete layer.

\section{Data Availability}

The data used to support the findings of this study are included within the article.

\section{Conflicts of Interest}

The authors declare that there are no conflicts of interest regarding the publication of this paper.

\section{References}

[1] V. Z. Vlasov, General Theory of Shells and its Applications in Engineering, NASA TT F-99, Washinton DC, USA, 1964.

[2] R. K. Zamani and M. R. Bidgoli, "Seismic response of smart nanocomposite cylindrical shell conveying fluid flow using HDQ-Newmark methods," Computers and Concrete, vol. 20, no. 6, pp. 671-682, 2017.
[3] S. L. Dong, G. B. Bai, X. Q. Zheng, and Y. Zhao, “A spherical lattice shell composed of six-bar tetrahedral units: configuration, structural behavior, and prefabricated construction," Advances in Structural Engineering, vol. 19, no. 7, pp. 1-12, 2016.

[4] F. Miao, S.-L. Dong, H.-Q. Liang, X.-T. Wang, X.-L. Zhu, and C. Ding, "Manufacture and prefabrication practice on a test model of a novel six-bar tetrahedral cylindrical lattice shell," Advances in Structural Engineering, vol. 22, no. 2, pp. 287296, 2018.

[5] B. Baby and L. G. Das, "Numerical study of concrete dome structure using ANSYS 17.0," IJIRSET, vol. 6, no. 5, pp. 8186-8193, 2017.

[6] H. D. Nguyen, "Compute the two-dimensional curved shell, the rectangular plan by the approximate method," Building science and technology journal, vol. 2, pp. 28-33, 2014.

[7] B. A. Harish, N. V. Ramana, and K. Manjunatha, "Finite element analysis of doubly curved thin concrete shells," International Journal of Engineering Science and Innovative Technology, vol. 4, no. 5, pp. 48-57, 2015.

[8] P. Sivakumar, K. Manjunatha, and B. A. Harish, "Experimental and FE analysis of funicular shells," International journal of engineering and innovative technology, vol. 4, no. 9, pp. 178-186, 2015.

[9] G. L. M. Danush, G. V. Sowjanya, and T. M. Siddesh, "Finite element analysis of doubly curved thin concrete shells with square and rectangular plan $15 \mathrm{~m} \times 15 \mathrm{~m}$ and $15 \mathrm{~m} \times 10 \mathrm{~m}$ under uniformly distributed load using Sap2000," IRJET, vol. 4, no. 6, pp. 560-564, 2017.

[10] S. S. Kadam, G. R. Gandhe, and D. H. Tupe, "Forced vibration analysis of invented umbrella roof shell using Ansys," IJRPET, vol. 3, no. 5, pp. 31-33, 2017.

[11] N. N. Meleka, M. A. Safan, A. A. Bashandy, and A. S. AbdElrazek, "Repairing and strengthening of elliptical paraboloid reinforced concrete shells with openings," Archives of Civil Engineering, vol. 59, no. 3, pp. 401-420, 2013.

[12] G. Stefano, V. Varano, G. Tomasello, and D. Alfonsi, "R"Funicularity of form found shell structures," Engineering Structures, vol. 157, pp. 157-169, 2018.

[13] E. Verwimp, T. Tysmans, M. Mollaert, and M. Wozniak, "Prediction of the buckling behaviour of thin cement composite shells: parameter study," Thin-Walled Structures, vol. 108, pp. 20-29, 2016.

[14] T. M. Jeyashree, C. Arunkumar, and K. S. Ashok, "Experimental and analytical study on funicular concrete shell foundation under ultimate loading," Asean journal of civil engineering, vol. 18, no. 6, pp. 863-878, 2017.

[15] R. Keikha, A. Heidari, H. Hosseinabadi, and M. S. Haghighi, "Classical shell theory for instability analysis of concrete pipes conveying nanofluid," Computers and Concrete, vol. 22, no. 2, pp. 161-166, 2018.

[16] L. Qi, X. Zhang, and H. Huo, "Design bearing capacity of the initial imperfect lattice shell," Advances in Structural Engineering, vol. 19, no. 1, pp. 14-22, 2016.

[17] C. Kämper, P. Forman, T. Stallmann, M. A. Ahrens, P. Mark, and J. Schnell, "Optimised high-performance concrete shells for parabolic trough collectors," Journal of the international association for shell and spatial structures, vol. 58, no. 1, pp. 105-119, 2017.

[18] H. Schmidt, "Stability of steel shell structures," Journal of Constructional Steel Research, vol. 55, no. 1-3, pp. 159-181, 2000. 
[19] H. C. Noh, "Ultimate strength of large scale reinforced concrete thin shell structures," Thin-Walled Structures, vol. 43, no. 9, pp. 1418-1443, 2005.

[20] W. Li, N. Nguyen-Thanh, and K. Zhou, "Geometrically nonlinear analysis of thin-shell structures based on an isogeometric-meshfree coupling approach," Computer Methods in Applied Mechanics and Engineering, vol. 336, pp. 111-134, 2018.

[21] S. A. Ambartsumyan, "Contributions to the theory of anisotropic layered shells," Applied Mechanics Reviews, vol. 15, pp. 245-249, 1962.

[22] A. J. M. Ferreira, E. Carrera, M. Cinefra, and C. M. C. Roque, "Analysis of laminated doubly-curved shells by a layerwise theory and radial basis functions collocation, accounting for through-the-thickness deformations," Computational Mechanics, vol. 48, no. 1, pp. 13-25, 2011.

[23] F. Tornabene, N. Fantuzzi, E. Viola, and J. N. Reddy, "Winkler-Pasternak foundation effect on the static and dynamic analyses of laminated doubly-curved and degenerate shells and panels," Composites Part B: Engineering, vol. 57, pp. 269-296, 2014.

[24] O. Allam, K. Draiche, A. A. Bousahla et al., "A generalized 4unknown refined theory for bending and free vibration analysis of laminated composite and sandwich plates and shells," Computers and Concrete, vol. 26, no. 2, pp. 185-201, 2020.

[25] L. Xie, X.. Lu, X. Lu, Y. Huang, and L. Ye, "Multi-layer shell element for shear walls in open sees," Computing in Civil and Building Engineering, vol. 2014, pp. 1190-1197, 2014.

[26] A. S. Chepurnenko, "Stress-strain state of three-layered shallow shells under conditions of nonlinear creep," Magazine of Civil Engineering, vol. 8, pp. 156-168, 2017.

[27] D. Veenendaal, J. Bakker, and P. Block, "Structural design of the flexibly formed, mesh-reinforced concrete sandwich shell roof of NEST HiLo," Journal of the international association for shell and spatial structures, vol. 58, no. 1, pp. 23-38, 2017.

[28] Z. W. Miao, X. Z. Lu, J. J. Jiang, and L. P. Ye, "Nonlinear FE model for RC shear walls based on multi-layer shell element and micro-plane constitutive model," Computational Methods in Engineering \& Science, p. 204, 2006.

[29] W. Chao, "The applicability study on the multi-layer shell element method in steel concrete structure of shield building," in Proceedings of International Conference on Nuclear Engineering, pp. 1-4, Shanghai, China, July 2017.

[30] T. M. D. Do and T. Q. K. Lam, "Design parameters of double layers steel fiber concrete beams," Lecture Notes in Civil Engineering, vol. 130, pp. 299-321, 2021.

[31] T. Q. K. Lam, T. M. D. Do, V. T. Ngo, T. T. N. Nguyen, and D. Q. Pham, "Concrete grade change in the layers of threelayer steel fibre reinforced concrete beams," Journal of Achievements in Materials and Manufacturing Engineering, vol. 1, no. 102, pp. 16-29, 2020.

[32] V. T. Ngo, T. Q. K. Lam, T. M. D. Do, and T. C. Nguyen, "Increased plasticity of nano concrete with steel fibers," Magazine of Civil Engineering, vol. 93, no. 1, pp. 27-34, 2020.

[33] V. T. Ngo, T. T. Bui, T. C. N. Nguyen, T. T. N. Nguyen, D. P. Nguyen, and T. Q. K. Lam, "Effect of nano-silica on fracture properties and crack extension resistance of highperformance concrete," in Proceedings of the International Conference on Computational Methods, pp. 137-148, Konstanz, Germany, September 2020.

[34] T. Q. K. Lam and T. M. D. Do, "Analysis of nonlinear material and steel fiber content in the double layers concrete shell," in
Proceedings of AIP Conference proceedings, Article ID 020008, Chennai, India, December 2020.

[35] TCVN 5574:2018, Design of Reinforced concrete Structures", Vietnam Standard, Hanoi, Vietnam, 2018. 